


\section{AS (IN)CERTEZAS DO TRABALHO DOCENTE NA PANDEMIA}

A ilustração da capa representa o contexto pelo qual se intensificaram as (in)certezas do trabalho docente durante a pandemia de Covid-19. São incertezas de uma nova realidade em que a humanidade buscou, na ciência, respostas para o enfrentamento do vírus, mas, ao mesmo tempo, a presunção das certezas decorrentes de ações governamentais desprovidas da ética e do compromisso com a integridade científica e proteção à vida. "Certezas" das dificuldades que o trabalho remoto impôs ao processo de ensinar e aprender diante das desigualdades sociais.

A singularidade do trabalho docente desenvolveu-se mediada pelas incertezas de ter vacinas, medicamentos, leitos hospitalares, insumos, medidas sanitárias eficazes, vínculos de empregos, salários... Incertezas geradas por um contexto conservador-reacionário, o qual submeteu os profissionais da educação à jornada exaustiva de trabalho acompanhada da retirada de direitos, causando adoecimento físico e emocional. No entanto, as incertezas tensionaram a certeza em fortalecer, no coletivo da classe trabalhadora, a resistência, em disputar o presente para assegurar no futuro, a democracia, a ciência, a educação, as instituições públicas e a justiça social.

A capa expressa as características das contradições do desenvolvimento do capital. Ao mesmo tempo que produz e acumula riqueza, esse desenvolvimento reproduz a desigualdade social, escancarada na pandemia pelo aumento da pobreza, do desemprego, da fome e da exclusão social. No caso da educação, milhares de crianças e jovens das escolas públicas sendo chamados a acessar salas virtuais, via dispositivos digitais, sem que as condições básicas de sobrevivência estivessem garantidas, tampouco as condições materiais e os meios tecnológicos para acessar tais ambientes.

O ciberespaço é retratado por meio da conectividade, via plataformas virtuais. Ele explicita a tendência de transformar o processo formativo-educativo em transmissão e desenvolvimento de atividades. A aula sendo reduzida ao momento do repasse do conteúdo, no qual o imediatismo pedagógico, além de coisificar o conhecimento, transforma 
o professor na antítese da essência do seu trabalho: de ensinar e educar a informar e repassar atividades.

O papel rasgado em branco denota a separação do espaço externo e interno. Ou seja, o distanciamento social necessário para diminuir a contaminação pelo vírus levou à oferta de aulas a distância, retirando a proximidade da vivência física, do abraço, da potência, da confluência de sentimentos e da interação humana, características da aula presencial e do trabalho pedagógico de ensinar e aprender. As câmeras desligadas, às vezes como condição para melhorar a estabilidade da rede ou proteger a privacidade, demonstram as novas relações sociais: frias, distantes, sem brilho, em que a relação dialógica, fundamental para o processo de ensino e aprendizagem, em grande medida é substituída pelo monólogo do professor que, frequentemente, "dialoga" com a tela do computador e a projeção de seus slides.

O celular em mãos indica a intensificação do trabalho, que exigiu dos professores múltiplas formas de comunicação simultâneas para tentar sanar as dúvidas e suprir as necessidades dos estudantes e das famílias e/ ou responsáveis. Entretanto, os professores insistem em manter os livros próximos de si, evidenciando sua relação com a produção e difusão do conhecimento, um ato de resistência. Livros!!! Expressão do conhecimento, da ciência, da cultura produzida pela humanidade, da esperança em escrever um novo projeto social coletivo em busca de alternativas justas de vida para todos e todas. Livros!!! Como forma de registrar o momento histórico, possibilitando a análise crítica da realidade social sobre o cotidiano do trabalho docente na pandemia.

Fonte da ilustração da capa: Criação a partir das figuras disponíveis gratuitamente no https://www.canva.com/design/ 


\author{
Ângela Maria Silveira Portelinha \\ Berenice Lurdes Borssoi \\ Egeslaine de $\mathrm{Nez}$ \\ Franciele Maria David \\ Keila Cristina Batista \\ Vanice Schossler Sbardelotto
}

\title{
AS (IN)CERTEZAS DO TRABALHO DOCENTE NA PANDEMIA
}

$1^{a}$ Edição Eletrônica

Uberlândia / Minas Gerais

Navegando Publicações

2021
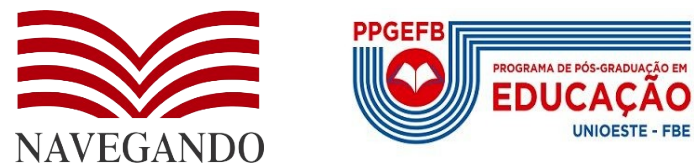
Navegando Publicações

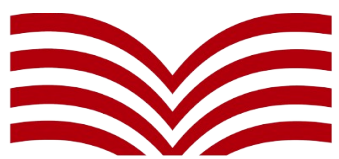

\section{NAVEGANDO}

www.editoranavegando.com

editoranavegando@gmail.com

Uberlândia - MG,

Brasil

Direção Editorial: Navegando

Projeto gráfico e diagramação: Lurdes Lucena

Arte da Capa: Gesfort

Revisão: Isaque Gomes Correa

Copyright (C) by autor, 2021.

A797 - PORTELINHA, Â. M. S.; et al. As (in)certezas do trabalho docente na pandemia. Uberlândia: Navegando Publicações, 2021.

ISBN: 978-65-86678-69-7

dol $10.29388 / 978-65-86678-69-7$

1. Educação 2. Trabalho docente 3. Pandemia Covid-19 I. Ângela Maria Silveira Portelinha; Berenice Lurdes Borssoi; Egeslaine de Nez; Franciele Maria David; Keila Cristina Batista; Vanice Schossler Sbardelotto II. Navegando Publicações. Título.

$$
\begin{array}{r}
C D D-370 \\
C D U-37
\end{array}
$$

\section{Índice para catálogo sistemático}


Navegando Publicações

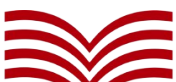

NAVEGANDO

\section{Editores}

Carlos Lucena - UFU, Brasil

José Claudinei Lombardi - Unicamp, Brasil

José Carlos de Souza Araújo - Uniube/UFU, Brasil

www.editoranavegando.com editoranavegando@gmail.com

Uberlândia - MG

Brasil

\section{Conselho Editorial Multidisciplinar}

Pesquisadores Nacionais

Afrânio Mendes Catani - USP - Brasil Anderson Brettas - IFTM - Brasil

Anselmo Alencar Colares - UFOPA - Brasil Carlos Lucena - UFU - Brasil

Carlos Henrique de Carvalho - UFU, Brasil

Cílson César Fagiani - Uniube - Brasil

Dermeval Saviani - Unicamp - Brasil

Elmiro Santos Resende - UFU - Brasil

Fabiane Santana Previtali - UFU, Brasil

Gilberto Luiz Alves - UFMS - Brasil Inez Stampa - PUCRJ - Brasil

João dos Reis Silva Júnior - UFSCar - Brasil

José Carlos de Souza Araújo - Uniube/UFU - Brasil

José Claudinei Lombardi - Unicamp - Brasil

Larissa Dahmer Pereira - UFF - Brasil

Lívia Diana Rocha Magalhães - UESB - Brasil

Mara Regina Martins Jacomeli - Unicamp, Brasil Maria J. A. Rosário - UFPA - Brasil

Newton Antonio Paciulli Bryan - Unicamp, Brasil

Paulino José Orso - Unioeste - Brasil

Ricardo Antunes - Unicamp, Brasil

Robson Luiz de França - UFU, Brasil

Tatiana Dahmer Pereira - UFF - Brasil

Valdemar Sguissardi - UFSCar - (Apos.) - Brasil

Valeria Lucilia Forti - UERJ - Brasi

Yolanda Guerra - UFRJ - Brasil

\section{Pesquisadores Internacionais}

Alberto L. Bialakowsky - Universidad de Buenos Aires - Argentina. Alcina Maria de Castro Martins - (I.S.M.T.), Coimbra - Portugal Alexander Steffanell - Lee University - EUA

Ángela A. Fernández - Univ. Aut. de St. Domingo - Rep. Dominicana Antonino Vidal Ortega - Pont. Un. Cat. M. y Me - Rep. Dominicana Armando Martinez Rosales - Universidad Popular de Cesar - Colômbia

Artemis Torres Valenzuela - Universidad San Carlos de Guatemala - Guatemala Carolina Crisorio - Universidad de Buenos Aires - Argentina Christian Cwik - Universität Graz - Austria Christian Hausser - Universidad de Talca - Chile Daniel Schugurensky - Arizona State University - EUA Elizet Payne Iglesias - Universidad de Costa Rica - Costa Rica Elsa Capron - Université de Nimés / Univ. de la Reunión - France Elvira Aballi Morell - Vanderbilt University - EUA.

Fernando Camacho Padilla - Univ. Autónoma de Madrid - Espanha Francisco Javier Maza Avila - Universidad de Cartagena - Colômbia Hernán Venegas Delgado - Univ. Autónoma de Coahuila - México Iside Gjergii - Universidade de Coimbra - Portugal

Iván Sánchez - Universidad del Magdalena -Colômbia Johanna von Grafenstein, Instituto Mora - México

Lionel Muñoz Paz - Universidad Central de Venezuela - Venezuela Jorge Enrique Elías-Caro - Universidad del Magdalena - Colômbia José Jesus Borjón Nieto - El Colégio de Vera Cruz - México

José Luis de los Reyes - Universidad Autónoma de Madrid - Espanha Juan Marchena Fernandez - Universidad Pablo de Olavide - Espanha Juan Paz y Miño Cepeda, Pont. Univ. Católica del Ecuador - Equador Lerber Dimas Vasquez - Universidad de La Guajira - Colômbia Marvin Barahona - Universidad Nacional Autónoma de Honduras - Honduras Michael Zeuske - Universität Zu Köln - Alemanha Miguel Perez - Universidade Nova Lisboa - Portugal

Pilar Cagiao Vila - Universidad de Santiago de Compostela - Espanha

Raul Roman Romero - Univ. Nacional de Colombia - Colômbia Roberto Gonzáles Aranas -Universidad del Norte - Colômbia

Ronny Viales Hurtado - Universidad de Costa Rica - Costa Rica

Rosana de Matos Silveira Santos - Universidad de Granada - Espanha Rosario Marquez Macias, Universidad de Huelva - Espanha Sérgio Guerra Vilaboy - Universidad de la Habana - Cuba Silvia Mancini - Université de Lausanne - Suíça

Teresa Medina - Universidade do Minho - Portugal Tristan MacCoaw - Universit of London - Inglaterra

Victor-Jacinto Flecha - Univ. Cat. N. Señora de la Asunción - Paraguai Yoel Cordoví Núñes - Instituto de História de Cuba v Cuba 
Se a contradição for o pulmão da história, o paradoxo deverá ser, penso eu, o espelho que a história usa para debochar de nós.

(Galeano, 2003) 
Dedicatória

Em momentos de crises, patencializadas por pandemias. a sociedade é chamada a refletir sobre a necessidade e a sentida do trabalho de algumas profissões. Este livra é dedicada as profissionais da educaçãa, que na cantexto da Covid-19. diante das incertezas e da intensificaçãa da trabalho, continuaram a ensinar $e$ a aprender. Ousaram a ressignificar suas práticas, manifestaram-se e resistiram aas ataques à educaçãa pública e nãa se ausentaram daquila que as constitui cama docentes: a compromissa política e sacial cam a processa formativa-educativa das criancas e dos jouens.

Nossa recanhecimenta! 


\section{SUMÁRIO}

PREFÁCIO

APRESENTAÇÃO

INTRODUÇÃO

1 ENCAMINHAMENTOS ADMINISTRATIVOS E PEDAGÓGICOS DA SEED/PR

2 O TRABALHO DOCENTE NA EDUCAÇÃO BÁSICA NO CONTEXTO DO COVID-19

2.1 A busca pelas informações com professores e pedagogos

2.2 A realidade sobre o trabalho docente na pandemia no Sudoeste do Paraná

2.2.1 Identificação, formação e trabalho

2.2.2 O trabalho docente remoto durante a pandemia - EaD

2.2.3 O trabalho docente e organização do trabalho pedagógico

CONCLUSÕES

REFERÊNCIAS

O Grupo de Pesquisa "Educação Superior, Formação e Trabalho Docente" (GESFORT) e suas pesquisadoras 


\section{PREFÁCIO ${ }^{1}$}

Realizar o prefácio do livro As (In)certezas do trabalho docente na pandemia foi uma atividade que me honrou e, ao mesmo tempo, possibilitou importantes aprendizagens. É oportuno ler um livro organizado por pesquisadoras que se dedicaram a ouvir professores neste contexto da pandemia de Covid-19 e de tamanho descaso de políticas efetivas de defesa da vida.

Viver o contexto pandêmico no Brasil, em que nesta data (05/05/2021) passamos de 414 mil vidas ceifadas pelo vírus, é angustiante e entristecedor. Tantas vidas que se foram e famílias deixadas em sofrimento pela partida de seus entes queridos.

Diante deste cenário, ressalta-se o descaso das políticas governamentais para que houvesse organicidade e ações que possibilitassem a vacinação e medidas mais duras de restrição, de isolamento social, ações que fossem orientadas, informadas e divulgadas por nossos governantes. Passamos por sucessivas trocas de ministros da Saúde, o que gerou e gera muita insegurança, descontinuidade e a não realização de um efetivo canal de diálogo e orientação à população brasileira. O que temos visto são decisões isoladas nos diferentes estados e cidades do Brasil.

O processo educacional e, mais especificamente, o trabalho dos professores e das professoras certamente foi e está sendo afetado, e o embate necessário pela defesa da vida está presente na pauta da maior parte dos docentes e de seus sindicatos. As escolas ainda não são locais em que os profissionais da educação se sentem seguros para retomar as atividades profissionais, e muitos pais, mães e responsáveis pelas crianças e jovens ainda precisariam sentir que a escola não é um espaço de transmissibilidade e de propagação do vírus da Covid-19.

Não é por acaso que muitas redes de ensino estão em movimento de greve, pela defesa da vida, atentos e preocupados com uma imposição de retorno presencial, sem planejamento e equipamentos de proteção necessários para garantir a saúde e a vida.

Desse modo, realizar o prefácio para um livro que tem como eixo central de discussão o trabalho docente no contexto da pandemia, ouvindo professores e analisando documentos, é extraordinário por constatar a

${ }^{1}$ DOI - 10.29388/978-65-86678-69-7-f.9-11 
enorme contribuição desta pesquisa para a área educacional. A investigação foi realizada pelo Grupo de Pesquisa "Educação Superior, Formação e Trabalho Docente" (GESFORT), da Universidade Estadual do Oeste do Paraná (UNIOESTE), campus de Francisco Beltrão, que teve como objetivos analisar as implicações do ensino a distância, via sistema remoto, para o traba Iho docente no contexto da Pandemia da Covid-19 e explicitar os conflitos e as contradições que envolvem as práticas institucionais, representadas pela Secretaria Estadual de Educação do Estado do Paraná (SEED) e a realidade dos professores/as vinculados a este sistema de ensino.

As pesquisadoras deste grupo de pesquisa, que organizaram esta obra, utilizaram um questionário com questões abertas e fechadas, enviado para mais de 4.200 profissionais da educação. Entre os respondentes estão professores/as e pedagogos/as de três cidades do Sudoeste do Paraná (Dois Vizinhos, Francisco Beltrão e Pato Branco).

Perceber que o GESFORT tem dados riquíssimos sobre o trabalho docente no contexto pandêmico e que traz à discussão, por meio desta divulgação, é o que se espera de pesquisadores e pesquisadoras que se mostram comprometidos com a realização e a divulgação de dados que retratem uma realidade emergente, que precisa ser registrada, ou mesmo, "fotografada", para análises presentes e futuras da história que estamos vivenciando.

Neste sentido, o trabalho realizado pelas/pelos docentes tem sido admirável, sendo concretizado por meio de investimento financeiro pessoal em equipamentos tecnológicos, melhoria da rede de internet, abertura de suas residências para que o trabalho compartilhe dos espaços familiares, da privacidade domiciliar, resultando em uma intensificação do trabalho, em que já não se tem mais parâmetro estabelecido para as pausas adequadas às refeições e de horário de descanso. É quase uma dedicação integral do tempo para atender a tantas solicitações de trabalho e para dar conta da vida privada, familiar que, não por acaso, tem gerado tanto adoecimento. Além desta intensificação do trabalho, as/os docentes precisam lidar e conviver com tantas mortes e adoecimento causados pela Covid-19 diariamente em nosso país. É a situação de muitos trabalhadores que, assim como os profissionais da educação, precisa ser sinalizada e compreendida como um verdadeiro desgaste da energia humana para sobreviver em meio ao caos.

Os docentes que foram "convocados" para trabalhar de forma presencial convivem com o receio de se deslocar até as instituições educativas, quando necessitam de transporte público, e com receio do contágio em 
seus espaços de trabalho. Convivem com o medo, receio e, não por acaso, o adoecimento psíquico tem tomado conta de muitos profissionais de educação, os quais vêm desenvolvendo quadros de depressão, síndrome de pânico etc.

Todas estas questões são ampliadas quando os/as docentes trabaIham em mais de uma escola, como mostram os dados levantados neste livro. Eles e elas necessitam dividir os recursos tecnológicos com outras pessoas das famílias que moram na mesma residência, cuidados com a vida, etc. Um dos quadros apresentados neste livro mostra os pontos positivos e negativos apontados pelos/as docentes sobre o trabalho da pandemia, que revela os desafios e dilemas diante de tal cenário. Dessa forma, pode-se afirmar que os professores e as professoras têm trabalhado e muito! Que também têm adoecido e realizado um grande investimento para que o processo de ensino e aprendizagem, neste contexto de excepcionalidade, continue se efetivando, mesmo que de forma diferenciada.

Não é por acaso que, conhecendo a realidade deste contexto pandêmico, a Associação Nacional pela Formação dos Profissionais da Educação (ANFOPE) tem se manifestado em defesa da vida. Para compreender melhor esta defesa, destaco três de treze pontos que os associados e as associadas da ANFOPE explicitam em uma carta durante o XX Encontro Nacional, ocorrido no início de fevereiro de 2021, em que se expressam a favor do a) do acesso universalizado, aos docentes e discentes, à internet e aos equipamentos tecnológicos através de plataformas educacionais públicas; b) da vacinação imediata da população brasileira, pelo SUS; e c) da garantia de vacinação a todos/as professores/as e trabalhadores/as não docentes para o retorno presencial à escola, assim como um rígido protocolo de biossegurança. ${ }^{2}$

Então, desejo uma boa leitura e que estes resultados possam contribuir para a compreensão do quanto os professores e professoras trabaIham em prol da educação.

Márcia de Souza Hobold Universidade Federal de Santa Catarina (UFSC) Vice-presidenta da Anfope - Região Sul

\footnotetext{
${ }^{2}$ Disponível em: http://www.anfope.org.br/cartas-e-manifestos/. Acesso em: 30 de abril de 2021
} 


\section{APRESENTAÇÃO}

O ano de 2020 começa com anúncio de uma crise sanitária movida pelo aparecimento de novo vírus causador da Covid-19, cuja origem e impacto para saúde mundial ainda eram desconhecidos. A perigosa difusão planetária do vírus se estendeu por todo o ano e adentrou 2021 interferindo na rotina social, econômica e cultural de povos e nações, pois o isolamento social e as longas quarentenas foram estratégias utilizadas para tentar conter o avanço da doença.

A Covid-19, ao ser declarada pela Organização Mundial de Saúde (OMS) como uma pandemia, pelos altos índices de contágios e pela rapidez de transmissão observadas em diversas regiões, acarretou a reconfiguração na organização da vida social causando um forte impacto. Assim, também a educação necessitou se reinventar em face do isolamento social e do lockdown em várias cidades. A pandemia impôs a urgência de estabelecer reconfigurações de atividades educativas no mundo.

Com a ausência de vacinas e um tratamento conhecido, os clamores das instituições científicas de pesquisa e da OMS foram ouvidos de alguma forma: "Não há outro jeito de impedir uma imensa catástrofe humanitária de alcance mundial do que as políticas de confinamento social" (COLEMARX, 2020, p. 6).

Houve a necessidade de promover políticas públicas de conscientização sobre o isolamento social, diante dos riscos da doença e de um possível colapso nos sistemas de saúde.

A respeito dos trabalhadores do sistema de saúde, Santos (2020, p. 15) esclarece que "qualquer quarentena é sempre discriminatória, mais difícil para uns grupos sociais do que para outros e impossível para um vasto grupo de cuidadores".

No caso dos sistemas de ensino, tanto no nível básico como superior e nas diversas modalidades, o isolamento social foi indispensável. Cada esfera administrativa - federal, estadual e municipal - enfrentou momentos desafiadores na organização do ensino. Os professores, para garantir o direito de ensino e aprendizagem, reinventavam-se cotidianamente e foram experienciando certezas e incertezas no processo pedagógico.

Portanto, embora os professores não foram considerados uma fração da classe trabalhadora que esteve "na vanguarda e suporta o peso de ser a força de trabalho que corre maior risco de contrair o vírus através de 
seus empregos ou de ser demitida injustamente por causa da retração econômica" (HARVEY, 2020, p. 21), eles, de outra forma, também foram impactados e chamados a continuar as atividades educacionais remotamente.

Em razão do necessário isolamento social, como forma de conter a propagação do vírus, alguns setores produtivos foram forçados a interromper seus processos de produção; fronteiras e comércios foram fechados em alguns períodos; atividades culturais e educacionais (escolas e universidades) foram suspensas por tempo indeterminado.

No entanto, Harvey (2020) postula que, embora tenha havido uma desaceleração imediata nos mercados financeiros globais quando a notícia se espalhou, passaram-se apenas alguns meses para que estes mercados se reorganizassem. Assim, a atividade educacional foi e é uma das que mais enfrentam desafios para reiniciar presencialmente.

Os efeitos epidemiológicos da Covid-19, por serem minimizados pelos governos brasileiros, com políticas sanitárias e encaminhamentos frágeis, escancararam, de um lado, a divisão de classes e, com isso, as desigualdades e as vulnerabilidades sociais; e, de outro lado, a intensificação e precarização do trabalho.

Antunes (2020) mostra que a letalidade da pandemia se estampa em sua aguda tragicidade em relação ao trabalho: se os trabalhadores, de um modo geral, voltarem ao labor, podem contaminar-se; se ficarem em isolamento, não terão recursos mínimos para a sobrevivência.

Os efeitos causados pela pandemia não são apenas epidemiológicos. No âmbito educacional, a primeira manifestação do Ministério da Educação (MEC) ocorreu em 17 de março de 2020, por meio da Portaria n.o 343 , que dispôs sobre a substituição das aulas presenciais por aulas em meios digitais (AGUIAR, 2020).

No mundo, centenas de pessoas ainda morrem diariamente em decorrência dos problemas relacionados à Covid-19. No Brasil, em outubro de 2020 foram contabilizados 5.170.996 de casos, com 152.513 mortes (CORONAVÍRUS BRASIL, 2020). Em alguns estados e municípios, obedecendo a um rigoroso controle sanitário e evidenciando a heterogeneidade da pandemia no país, presenciamos, no mesmo mês, o retorno gradual das aulas nas instituições de educação com ensino presencial, híbrido e não presencial, ou seja, educação realizada a distância.

No entanto, a educação à distância (EaD) requer planejamento, recursos técnicos e tecnológicos e formação profissional. A Campanha Nacional pelo Direito à Educação (2020) alerta que é um equívoco pensar que se 
faz EaD com transposição das aulas para um ambiente virtual, ou transformar ambientes virtuais de aprendizagem (AVA) em repositórios de textos e vídeos, para que as escolas e redes estejam em dia com seu dever de educar.

A vertente de ensino remoto é uma alternativa para manter a concentração dos alunos nos estudos, promover debates e informações para além dos componentes curriculares, mas não para prosseguir com o ano letivo, como se estivéssemos em uma situação de normalidade.

Vale ressaltar que, segundo a pesquisa TIC Domicílios 2019, apenas $42 \%$ das casas brasileiras têm computador; $85 \%$ dos usuários de internet das classes $D$ e $E$ acessam a rede somente pelo celular. A União Nacional dos Dirigentes Municipais de Educação (UNDIME) e a Rede Nacional Primeira Infância (RNPI) advertem que é fundamental outro tipo de abordagem para garantir o processo de ensino e aprendizagem.

Tendo em vista essas adversidades e consequências no sistema de educação no Brasil, as escolas defrontam-se com desafios sem precedentes, para os quais buscam respostas. Todas ainda se encontram sem rumo, refletindo e analisando o que e como será o pós-pandemia e a retomada das aulas presenciais totais ou com a possibilidade de ensino híbrido.

Considerando-se que a pandemia está longe do fim e que as pressões para o retorno da eufemisticamente denominada "nova normalidade" concorrerão para o retorno dos estudantes e profissionais da educação às escolas. Aguiar (2020) aponta que se vislumbra uma profunda mudança nas relações pedagógicas resultante de novas formas de apreensão do conhecimento. Por fim, ainda refletindo sobre a situação futura da escola, diz que é difícil descobrir como será o primeiro ano pós-pandemia. 


\section{INTRODUÇÃO}

No mês de março de 2020, em decorrência da pandemia de Covid19, o governo do Paraná decretou, como medida preventiva à disseminação do vírus, ações de distanciamento e isolamento social. Uma delas foi a suspensão das aulas presenciais na rede de educação básica e nas instituições de ensino superior. Com a suspensão das aulas no período da pandemia, alternativas para substituir as aulas presenciais pela oferta do ensino a distância foram implementadas. Considerou-se a necessidade de continuar as atividades do ano letivo justificando-se pelas perdas no processo formativo dos estudantes.

As aulas não presenciais evidenciaram muitos problemas em relação ao processo de ensino e aprendizagem: a falta de acesso às tecnologias; a exposição longa e contínua dos estudantes e professores frente aos computadores; desigualdade social acompanhada de exclusão digital; extensiva jornada de trabalho requerida aos profissionais da educação e a intensifica ção da burocracia e do controle relativos ao trabalho docente; a dificuldade de organizar o espaço e o tempo entre trabalho profissional, trabalho doméstico e acompanhamento de atividades escolares, para aqueles que têm filhos. Marcado por muitas alterações dos encaminhamentos administrativos e pedagógicos, devido às incertezas da realidade pandêmica, este período exigiu extensiva jornada de trabalho de todos os envolvidos com a educação escolar.

Diante deste contexto, o Grupo de Pesquisa "Educação Superior, Formação e Trabalho Docente" (GESFORT), da Universidade Estadual do Oeste do Paraná (UNIOESTE), campus de Francisco Beltrão, realizou uma pesquisa com o objetivo de analisar as implicações do ensino a distância, via sistema remoto, para o trabalho docente no contexto da pandemia de Covid-19. O intuito foi explicitar os conflitos e as contradições que envolvem as práticas institucionais, representadas pela Secretaria Estadual de Educação do Estado do Paraná (SEED/PR) e a realidade dos professores vinculados a este sistema de ensino.

Como procedimentos metodológicos, utilizamos a pesquisa documental e exploratória com levantamento de dados via questionário direcionados a professores e pedagogos do Sudoeste do Paraná (Núcleos Regionais de Educação de Dois Vizinhos, Francisco Beltrão e Pato Branco). O número de professores e pedagogos vinculados aos núcleos da Região Sudo- 
este foram coletados na página eletrônica da SEED, onde obteve-se o seguinte resultado: Núcleo de Francisco Beltrão: 1.816, Núcleo de Pato Branco: 1.787: Núcleo de Dois Vizinhos: 621, perfazendo um total de 4.224 professores e pedagogos. Devido à rotatividade na contratação dos profissionais da educação, consideraram-se os dados do mês de abril de 2020 como referência ao universo da amostra. Foi elaborado um questionário com questões abertas e fechadas na ferramenta Google Forms e enviado aos emails das escolas, listas de e-mails de professores e pedagogos e disponibilizado nas redes sociais e contatos de celular.

A pesquisa foi iniciada na segunda quinzena de maio de 2020 e encerrou-se em 30 de junho de 2020. Responderam ao questionário 619 profissionais da educação. $O$ questionário abordou três dimensões:

a) Identificação, formação e trabalho.

b) O trabalho docente remoto durante a pandemia - EaD.

c) O trabalho docente e organização do trabalho pedagógico.

Este livro está organizado em duas partes: na primeira, descrevemos os procedimentos realizados pela SEED/PR em relação à organização das atividades escolares no período de isolamento social. Trata-se de apresentar o conjunto de instruções de serviço, portarias e resoluções direcionadas às aulas não presenciais. É interessante destacar que os documentos utilizados para a pesquisa foram compilados e disponibilizados com os links nessa obra, pois entendemos que poderão ser objeto de consulta para estudos e análises posteriores sobre este momento histórico da educação paranaense.

Na segunda parte, apresentamos a sistematização das respostas coletadas de um grupo específico de profissionais da educação, os quais avaliam o trabalho docente no contexto da Covid-19. O propósito, neste momento, é apenas publicar os dados coletados, sem a pretensão de análises aprofundadas, pois, diante das incertezas e da rapidez com que ocorrem as mudanças nos sistemas de ensino, é fundamental disponibilizar os dados absolutos que podem subsidiar pesquisas futuras.

Esperamos que os resultados apresentados sejam objeto de reflexão e compreensão frente ao trabalho dos professores neste momento de pandemia, visto que há inúmeras situações e particularidades que envolvem o trabalho escolar. Essas merecem todo o respeito e apoio diante das condições sociais, materiais e de cuidado à saúde dos profissionais da educação e dos estudantes. 


\section{ENCAMINHAMENTOS ADMINISTRATIVOS E PEDAGÓGICOS DA SEED/PR}

O mês de março de 2020 começa diferente dos outros. O avanço da Covid-19 no Brasil torna-se realidade, a insegurança frente a este novo vírus impõe, aos sistemas de educação brasileiro, repensar a estrutura, a forma e a organização escolares. Medidas de enfrentamento são implementadas nas escolas, universidades e outros. No Paraná, o Decreto Estadual n.o 4.230/2020 (Diário Oficial de 16/03/2020) apresenta medidas para o enfrentamento da emergência de saúde pública de importância internacional decorrente do Coronavírus - Covid-19. Para tanto, o Art. $7^{\circ}$, orienta que

Os titulares dos Órgãos e Entidades compreendidos no art. $1^{\circ}$ deste Decreto poderão, após análise justificada da necessidade administrativa e, dentro da viabilidade técnica e operacional, suspender, total ou parcialmente, o expediente do Órgão ou Entidade, assim como atendimento presencial ao público, bem como instituir o regime de teletrabalho para os servidores, resguardando, para manutenção dos serviços considerados essenciais, quantitativo mínimo de servidores em sistema de rodízio, através de escalas diferenciadas e adoções de horários alternativos. (PARANÁ, 2020a, p. 4)

Após a publicação do decreto, nos dias 17, 18 e 19 de março de 2020, nas escolas e colégios ocorreram atividades de orientação e conscientização quanto aos protocolos de higiene e etiqueta respiratória, bem como ações relacionadas à importância do distanciamento social junto a funcionários, estudantes, famílias e responsáveis. Os alunos, professores e funcionários que apresentassem comorbidades de saúde seriam dispensados de suas respectivas funções. É importante salientar que esses dias de orientações nas escolas foram permeados por intensas discussões entre os docentes e funcionários; o nervosismo e tensão estavam presentes no espaço escolar.

O então secretário da Educação e do Esporte, Renato Feder, por meio do Decreto n.o 4.320 de 23/03/2020, regulamenta a suspenção das aulas presenciais: 
Art. 8ㅇ As aulas presenciais em escolas estaduais públicas e privadas, inclusive nas entidades conveniadas com o Estado do Paraná, e em universidades públicas ficam suspensas a partir de 20 de março de 2020". Parágrafo único. O período de suspensão poderá ser compreendido como antecipação do recesso escolar de julho de 2020, a critério da autoridade superior dos Órgãos e Entidades relacionados no caput deste artigo. (PARANÁ, 2020a, p. 5)

O Conselho Estadual de Educação do Paraná, em 31 de março de 2020, se pronunciou através da Deliberação $n$. o 01/2020, sobre a oferta de aulas não presenciais. Indica o regime especial para o desenvolvimento das atividades escolares, em seu art. 20: "Fica autorizada às instituições de ensino credenciadas e com cursos e modalidades já autorizados e/ou reconhecidos de Educação Básica e Educação Superior, com exceção para a educação infantil, a oferta de atividades não presenciais". Diante do cenário e da suspensão das aulas, ocorreu a antecipação do recesso escolar previsto do mês julho, através da Resolução n.o 1.249/2020 - GS/SEED, que dispõe sobre a adequação do calendário escolar de 2020 para a rede pública e estadual de educação básica.

A Resolução da SEED n.ㅇ 1.016, de 3 de abril de 2020, estabelece em regime especial as atividades escolares na forma de aulas não presenciais. Conforme artigo 3 o do documento, atividades escolares não presenciais

São aquelas utilizadas pelo professor da turma ou pelo componente curricular destinadas à interação com o estudante por meio de orientações impressas, estudos dirigidos, quizzes, plataformas virtuais, correio eletrônico, redes sociais, chats, fóruns, diário eletrônico, videoaulas, audiochamadas, vídeochamadas e outras assemelhadas. (PARANÁ, 2020g, Art. 3으)

No Quadro 1, são apresentados os documentos orientadores do processo educacional nesse período, com interferência na carreira dos professores. Observa-se a dinâmica dos documentos, que exigiram adequação e ajuste por parte das equipes pedagógicas das escolas em curtos espaços de tempo. 
Quadro 1 - Documentos sobre educação não presencial

\begin{tabular}{|c|c|c|}
\hline Data & Documentos* & Descrição \\
\hline $16 / 03 / 2020$ & $\begin{array}{l}\text { Decreto n. } 94.230- \\
\text { Governo do Estado } \\
\text { PR }\end{array}$ & $\begin{array}{l}\text { Dispõe sobre as medidas para enfren- } \\
\text { tamento da emergência de saúde pú- } \\
\text { blica de importância internacional de- } \\
\text { corrente do Coronavírus - Covid-19. }\end{array}$ \\
\hline Disponível em: & \multicolumn{2}{|l|}{ https://bit.ly/3ptoAdz } \\
\hline $18 / 03 / 2020$ & $\begin{array}{l}\text { Resolução n.o } \\
891 / 2020-\text { GS/ } \\
\text { SEED }\end{array}$ & $\begin{array}{l}\text { Estabelece medidas previstas nos De- } \\
\text { cretos n.o 4.230, de } 16 \text { de março de } \\
2020 \text {, e n.o 4.258, de } 17 \text { de março de } \\
\text { 2020, no âmbito da Secretaria de Es- } \\
\text { tado da Educação e do Esporte. }\end{array}$ \\
\hline Disponível em: & \multicolumn{2}{|c|}{ https://bit.ly/3ipTbHI } \\
\hline $20 / 03 / 2020$ & $\begin{array}{l}\text { Decreto n.o } 4312- \\
\text { Governo do Estado } \\
\text { PR }\end{array}$ & $\begin{array}{l}\text { Concede licença especial, de acordo } \\
\text { com o art. } 4 \text { \% da Lei Complementar n. } \\
\text { o } 217 \text { de } 22 \text { de outubro de } 2019 \text {, con- } \\
\text { forme específica. }\end{array}$ \\
\hline Disponível em: & \multicolumn{2}{|l|}{ https://bit.ly/3fSg3y5 } \\
\hline $23 / 03 / 2020$ & $\begin{array}{l}\text { Decreto n. } 9.320- \\
\text { Governo do Estado } \\
\text { PR }\end{array}$ & $\begin{array}{l}\text { Altera dispositivos do Decreto no } \\
4.312 \text {, de } 20 \text { de março de } 2020 \text { e do } \\
\text { Decreto no } 4.230 \text {, de } 16 \text { de março de } \\
2020 \text {. }\end{array}$ \\
\hline Disponível em: & \multicolumn{2}{|l|}{ https://bit.ly/2S4rb1U } \\
\hline $31 / 03 / 2020$ & 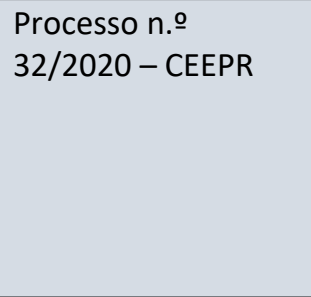 & $\begin{array}{l}\text { Instituição de regime especial para o } \\
\text { desenvolvimento das atividades esco- } \\
\text { lares no âmbito do Sistema Estadual } \\
\text { de Ensino do Paraná em decorrência } \\
\text { da legislação específica sobre a pan- } \\
\text { demia causada pelo novo Coronavírus } \\
\text { - Covid-19 e outras providências. }\end{array}$ \\
\hline Disponível em: & \multicolumn{2}{|l|}{ https://bit.ly/3yZQgvo } \\
\hline $03 / 04 / 2020$ & $\begin{array}{l}\text { Resolução n.ㅇ } \\
1.014 / 2020-\text { GS/ } \\
\text { SEED }\end{array}$ & $\begin{array}{l}\text { Dispõe sobre o chamamento em cará- } \\
\text { ter emergencial de professores do } \\
\text { Quadro Próprio de Magistério - QPM } \\
\text { e professores contratados em Regime } \\
\text { Especial - CRES (PSS) para comporem } \\
\text { o grupo de trabalho com vistas à pro- } \\
\text { dução de material audiovisual desti- } \\
\text { nado a estudantes da Educação Básica } \\
\text { da Rede Estadual de Ensino. }\end{array}$ \\
\hline
\end{tabular}




\begin{tabular}{|c|c|c|}
\hline Disponível em: & \multicolumn{2}{|c|}{ https://bit.ly/3po1o0L } \\
\hline $03 / 04 / 2020$ & $\begin{array}{l}\text { Resolução } n . \text { o } \\
1.016 / 2020-\text { GS/ } \\
\text { SEED }\end{array}$ & $\begin{array}{l}\text { Estabelece em regime especial as ati- } \\
\text { vidades escolares na forma de aulas } \\
\text { não presenciais, em decorrência da } \\
\text { pandemia causada pela Covid-19. }\end{array}$ \\
\hline Disponível em: & \multicolumn{2}{|c|}{ https://bit.ly/3pydapz } \\
\hline $20 / 04 / 2020$ & $\begin{array}{l}\text { Resolução n.․ } \\
1.249 / 2020-G S / \\
\text { SEED }\end{array}$ & $\begin{array}{l}\text { Dispõe sobre a adequação do Calen- } \\
\text { dário Escolar } 2020 \text { para a Rede Públi- } \\
\text { ca Estadual de Educação Básica. }\end{array}$ \\
\hline Disponível em: & \multicolumn{2}{|c|}{ https://bit.ly/3z39UH2 } \\
\hline $28 / 04 / 2020$ & $\begin{array}{l}\text { Orientação n.․ } \\
\text { 07/2020-DEDUC/ } \\
\text { SEED }\end{array}$ & $\begin{array}{l}\text { Em decorrência da pandemia causada } \\
\text { pela Covid-19, orienta sobre os proce- } \\
\text { dimentos para o atendimento aos es- } \\
\text { tudantes da Educação Profissional, } \\
\text { matriculados na rede pública estadual } \\
\text { de ensino do Paraná, em atendimento } \\
\text { à } \\
\text { Resolução n. } 1.016 / 2020 \text { - GS/SEED }\end{array}$ \\
\hline Disponível em: & \multicolumn{2}{|c|}{ https://bit.ly/34PAwgM } \\
\hline $28 / 04 / 2020$ & 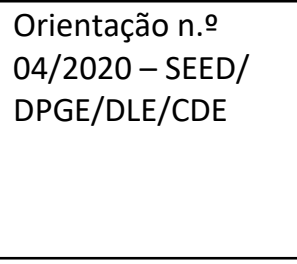 & $\begin{array}{l}\text { Orienta sobre os registros no livro de } \\
\text { registros de classe on-line - LRCO } \\
\text { para a rede Estadual de Ensino do Es- } \\
\text { tado do Paraná para o período de en- } \\
\text { frentamento ao surto do novo coro- } \\
\text { navírus (Covid -19). }\end{array}$ \\
\hline Disponível em: & \multicolumn{2}{|c|}{ https://bit.ly/3x0YWj8 } \\
\hline $28 / 04 / 2020$ & $\begin{array}{l}\text { Resolução } n . \text { o } \\
1.259 / 2020-\text { GS/ } \\
\text { SEED }\end{array}$ & $\begin{array}{l}\text { Altera a Resolução n. } 1.016 \text { - GS/ } \\
\text { SEED, de } 2020 .\end{array}$ \\
\hline Disponível em: & \multicolumn{2}{|l|}{ https://bit.ly/3z1JoO4 } \\
\hline $28 / 04 / 2020$ & $\begin{array}{l}\text { Resolução n.․ } \\
1.253 / 2020-G S / \\
\text { SEED }\end{array}$ & $\begin{array}{l}\text { Altera a Resolução n.o } 891 \text { - GS/SEED, } \\
\text { de } 18 \text { de março de } 2020 \text {. }\end{array}$ \\
\hline Disponível em: & \multicolumn{2}{|l|}{ https://bit.ly/3clESAq } \\
\hline $07 / 05 / 2020$ & $\begin{array}{l}\text { Resolução } n . \text { o } \\
1.522 / 2020-\text { GS/ } \\
\text { SEED }\end{array}$ & $\begin{array}{l}\text { Estabelece em regime especial as ati- } \\
\text { vidades escolares na forma de aulas } \\
\text { não presenciais em decorrência da } \\
\text { pandemia causada pela Covid-19. }\end{array}$ \\
\hline Disponível em: & \multicolumn{2}{|l|}{ https://bit.ly/2SZ294a } \\
\hline $07 / 05 / 2020$ & $\begin{array}{l}\text { Comunicado n. } .9 \\
06 / 2020-C D E /\end{array}$ & $\begin{array}{l}\text { Registro de frequência, conteúdo e } \\
\text { avaliação. }\end{array}$ \\
\hline
\end{tabular}




\begin{tabular}{|c|c|c|}
\hline & DLE/DPGE/SEED & \\
\hline Disponível em: & \multicolumn{2}{|c|}{ https://bit.ly/34Rlqam } \\
\hline $12 / 05 / 2020$. & $\begin{array}{l}\text { Resolução n.․ } \\
1.611 / 2020-\text { GS/ } \\
\text { SEED }\end{array}$ & $\begin{array}{l}\text { Altera a Resolução n. } 9891 \text { - GS/SEED, } \\
\text { de } 18 \text { de março de } 2020 .\end{array}$ \\
\hline Disponível em: & \multicolumn{2}{|c|}{ https://bit.ly/3yzQLFM } \\
\hline $12 / 05 / 2020$ & $\begin{array}{l}\text { Ofício Circular n. } \\
041 / 2020- \\
\text { DEDUC/SEED }\end{array}$ & $\begin{array}{l}\text { Procedimentos para o atendimento } \\
\text { dos estudantes no Google Classroom. }\end{array}$ \\
\hline Disponível em: & \multicolumn{2}{|c|}{ https://cutt.ly/Gnc6LtY } \\
\hline $15 / 05 / 2020$ & $\begin{array}{l}\text { Resolução } n . \stackrel{9}{1} \\
1733 / 2020-\text { GS/ } \\
\text { SEED }\end{array}$ & $\begin{array}{l}\text { Altera e acresce dispositivos à } \\
\text { Resolução n.o } 891 \text { - GS/SEED, de } \\
2020 .\end{array}$ \\
\hline Disponível em: & \multicolumn{2}{|l|}{ https://bit.ly/3fSj15H } \\
\hline $29 / 05 / 2020$. & $\begin{array}{l}\text { Ofício Circular n. } 9 \\
\text { 047/2020 -DEDUC/ } \\
\text { SEED. }\end{array}$ & $\begin{array}{l}\text { Retomada de conteúdos do } 1 \text { o trimes- } \\
\text { tre na semana do dia } 1 \text { a } 5 \text { de junho } \\
\text { de } 2020 .\end{array}$ \\
\hline Disponível em: & \multicolumn{2}{|l|}{ http } \\
\hline
\end{tabular}

Fonte: Nossa autoria.

Aos alunos sem acesso à internet e aos meios tecnológicos, regulamentou-se que a escola deveria fazer a entrega de kits de atividades impressas, de modo a proporcionar-Ihes o contato com as atividades. Tanto as atividades on-line como as impressas serviram para validar e controlar a frequência e a participação sendo parte do processo avaliativo. $O$ estado disponibilizou aos professores e alunos o acesso às atividades via aplicativo Aula Paraná, sala de aula virtual Google Classroom e Google Forms, vinculados ao e-mail @escola.

Dentre os aspectos a considerar, ressalta-se que, no início da implementação das atividades remotas, houve resistência por parte dos docentes e responsáveis, que discordaram das medidas e proposições do governo. No entanto, o cenário exigiu, mesmo que resistindo, a adesão da proposta da Secretaria de Educação. Destaca-se que as medidas do governo, em vez de serem inclusivas, geraram a exclusão no contexto geral, pois desconsiderou-se o acesso tecnológico de grande parte dos estudantes, bem como a necessidade de auxílio para desenvolveram as atividades impressas. As escolas e professores tiveram que buscar meios para contatar os alunos, utilizaram WhatsApp, telefone, redes sociais e visitas locais às famílias, de modo que os conteúdos e conhecimentos fossem garantidos neste período. 
Durante a implementação dos decretos, normativas, orientações, da SEED e do Conselho Estadual de Educação (CEE), professores, funcionários, comunidade escolar e Sindicato dos Profissionais de Educação (APP) se mobilizaram e articularam uma ampla frente de discussão sobre o cenário educacional que se anunciava.

Através das redes sociais ou nos grupos de WhatsApp das escolas, professores e funcionários debateram e argumentaram sobre a forma de implementação do ensino remoto. O sindicato dos professores do Paraná lançou notas contrárias à implementação, assim como orientações para a comunidade escolar, sobre as consequências desta modalidade de ensino imposta pela pandemia.

Para além da falta de infraestrutura e formação, os professores denunciaram a dificuldade de acesso dos estudantes da rede, além da desigualdade social que se escancarou neste momento.

As condições materiais de milhares de estudantes paranaenses são desveladas neste cenário, e, segundo reportagem na página da APP- Sindicato $^{3}$, apenas $30 \%$ dos matriculados estão assistindo as aulas pela TV, e ainda destaca que a metodologia implementada sem diálogo com a comunidade escolar é restritiva e excludente. Isso ocorre porque

Nossos estudantes não têm acompanhado o andamento das atividades no ritmo imposto pela mantenedora. Aulas televisivas padronizadas, aplicativos com baixíssimo acesso, restrição de deslocamento por risco de contágio são só alguns dos fatores que comprometem de forma irresponsável o processo de ensino e aprendizagem. (APP, 2020, p. 01)

Para além disso, o baixo número de acesso dos estudantes nas plataformas disponibilizadas evidencia a dificuldade dos estudantes em acessarem às aulas e atividades, e o esforço extenuante das equipes gestoras, pedagógicas e docentes sobre o rendimento escolar, levando estes profissionais à exaustão física e mental.

É importante considerar que no início desse processo a formação para professores, equipes pedagógicas e gestoras da escola demorou para ser ofertada. Os profissionais da educação foram encaminhados a esta nova realidade escolar sem nenhum tipo de suporte ou formação pedagógica, técnica, e ainda sem condições materiais para realizar atendimentos ou mesmo ministrar aulas por estas plataformas. A maioria desconhecia ou

\footnotetext{
${ }^{3}$ Disponível em: https://bit.ly/3fWOK7A. Acesso em: 15 nov. 2020.
} 
mesmo nunca havia trabalhado no sistema remoto de ensino, e os estudantes viram-se imersos em plataformas de ensino virtuais, das quais nunca tinham ouvido falar.

Os profissionais de educação ${ }^{4}$, mesmo sem formação adequada, orientaram e ensinaram estudantes nas condições mais adversas possíveis. Muitos professores e professoras adoeceram mentalmente e o cansaço físico tomou conta da categoria. A APP-Sindicato criou grupos virtuais para apoio psicológico aos profissionais da educação, e algumas centenas de estudantes evadiram-se das salas de aulas virtuais por não darem conta da demanda de atividades oferecidas.

Mesmo com toda essa dificuldade pedagógica, o governo se preocupou em criar estratégias de controle dos estudantes e professores. Primeiro, por meio dos tutoriais de ensino, que deveriam ser realizados no Google Meet e, caso não ocorresse a mobilização dos estudantes pelos professores, estes poderiam ser punidos com faltas. Porém, a categoria, juntamente com a APP-Sindicato, acionou os meios jurídicos, fazendo a SEED retroceder dessa orientação.

O governo entendeu que a responsabilidade do não acesso às aulas seria dos professores e equipes gestoras, desconsiderando as condições materiais que os estudantes das escolas públicas paranaense enfrentavam, tais como acesso à internet, ausência de aparelhos de celulares e computadores por parte das famílias, internet com pouca capacidade ou sinal incompatível com os aplicativos que necessitavam ser acessados. Os estudantes que realizavam atividades com o material impresso e assistiam às aulas pela TV, em canal específico para isso, apresentaram dificuldades para acompanhar e/ou entender as atividades disponibilizadas pela SEED.

Importa destacar que, mesmo diante do cenário pandêmico e das especificidades e dificuldades ora relatadas, as direções, equipes pedagógicas, professores e funcionários uniram esforços para mobilizar os estudantes e seus respectivos responsáveis para participar das atividades letivas de 2020. Sabemos que dentro das condições materiais, sociais e econômicas presentes no processo, isso não foi totalmente possível para garantir que o aprendizado acontecesse.

Reiteramos que o trabalho realizado nas escolas é de suma importância para garantir que o aprendizado e que a figura do professor sejam

\footnotetext{
${ }^{4}$ Por profissionais de educação queremos dizer todos os trabalhadores e trabalhadoras envolvidos na organização escolar, agentes I, agentes II, professores pedagogos e direção escolar.
} 
essenciais na dinamização e no processo de apropriação dos conhecimentos. A pandemia mostrou que a escola possui um papel determinante na formação das crianças e jovens quanto à apropriação de conhecimentos, e vivência e participação social. Este tempo trará implicações ao processo formativo/educativo dos estudantes, considerando que as aulas presenciais são espaços de conhecimento, socialização, debates e de novas apropriações que estão intrinsecamente ligados à formação humana. 


\section{2 \\ O TRABALHO DOCENTE NA EDUCAÇÃO BÁSICA NO CONTEXTO DA COVID-19}

A pesquisa em educação precisa explicar a realidade sobre os processos educativos. A pandemia de Covid-19 trouxe uma situação inaugural para a organização do trabalho pedagógico nas escolas. A suspensão das atividades presenciais no ano de 2020 requisitou, de instituições e professores, a reorganização do processo educativo. No Paraná, as atividades escolares presenciais foram suspensas em março e, desde então, instituições, professores, famílias e estudantes buscam dar continuidade ao processo educativo com desafios para todos os envolvidos. Neste capítulo, apresentamos a metodologia e os resultados alcançados da pesquisa intitulada "O Trabalho Docente na Educação Básica no Contexto da Covid-19".

\subsection{A busca pelas informações com professores e pedagogos}

A pesquisa "O Trabalho Docente na Educação Básica no Contexto da Covid-19", desenvolvida pelo GESFORT, buscou apresentar o conjunto legal emanado da Secretaria Estadual de Educação do Paraná para disciplinar e orientar o trabalho docente durante a pandemia e captar as condições objetivas de trabalho docente dos professores nesse período. Entre estas estão as condições de trabalho em casa, a posse dos meios tecnológicos adequados para a realização das atividades letivas e as impressões gerais sobre o trabalho nessas condições. Com isso, pretendemos oferecer ao leitor um conjunto de documentos, de forma organizada, e de dados captados junto aos professores sobre o trabalho docente neste contexto pandêmico.

As pesquisas que pretendem responder questões objetivas de conhecimento de uma realidade, por meio de survey, são do tipo de pesquisa de levantamento ou exploratória (YIN, 2015). A opção foi utilizar o método de survey para identificar as condições de trabalho dos professores na pandemia. Por ser um método adequando à descrição e verificação de prevalência dos fatores, conforme Yin (2015), os dados coletados e apresentados podem ensejar questionamentos, estudos e análises, constituindo-se em fonte de informação sobre um período específico vivido pelos professores. 
A pandemia de Covid-19 provocou alterações significativas no trabalho docente em um curto espaço de tempo, exigindo adaptação do modo de trabalho, nos equipamentos, espaços e tempos. Os professores tiveram que desempenhar suas atividades mediados por recursos tecnológicos, de forma não presencial, geralmente em suas casas. Essas mudanças, que surpreenderam professores, pais, estudantes, marcaram de formas diferenciadas todos os sujeitos envolvidos.

Foi possível, por meio do questionário, coletar informações e conhecer as condições de realizar o trabalho docente dos professores da Rede Estadual de Educação, nos Núcleos Regionais de Dois Vizinhos, Francisco Beltrão e Pato Branco, pois os dados dessa pesquisa, a partir desse método,

[...] facilitam a abertura da ciência. Já que a pesquisa de survey envolve a coleta e quantificação dos dados, os dados coletados se tornam fonte permanente de informações. Um corpo de dados de survey pode ser analisado pouco depois da coleta e confirmar uma determinada teoria de comportamento social. Se a própria teoria sofrer modificações mais tarde, é sempre possível retornar ao conjunto de dados e reanalisá-los sob a nova perspectiva teórica. (BABBIE, 2001, p. 86)

Para isso, recorreu-se aos questionários, pois os "surveys são muito semelhantes a censos, sendo a diferença principal entre eles que um survey, tipicamente, examina uma amostra de população, enquanto o censo geralmente implica uma enumeração da população toda" (BABBIE, 2001, p. 78). Desta forma, a população estudada foi o conjunto dos professores e professoras, pedagogos e pedagogas dos Núcleos Regionais de Educação (NREs) citados, cuja amostra estudada foram os respondentes.

Assim, os professores e pedagogos destes núcleos foram convidados e tiveram a oportunidade de responder à pesquisa. O questionário foi elaborado pelo grupo de professoras pesquisadoras do GESFORT, abrangendo aspectos de identificação, de formação e trabalho, perguntas sobre o trabalho docente não presencial, bem como questões do trabalho docente e organização do trabalho pedagógico. Para a aplicação do questionário aos docentes e pedagogos, ele foi enviado aos endereços eletrônicos das escolas, dos diretores, com ampla divulgação em redes sociais. Em um segundo momento foi divulgado aos professores, por aplicativo de mensagem. 
O questionário foi estruturado em três blocos, com um total de 26 questões fechadas: 24 de múltipla escolha, 2 com caixa de seleção e 2 questões abertas. O primeiro bloco dirigiu-se à caracterização das especificidades do público, como idade, sexo, formação, entre outras. O segundo bloco versou sobre as condições materiais de realização do trabalho não presencial, posse de recursos tecnológicos, condições domiciliares, conhecimento sobre plataformas e aplicativos utilizados. O terceiro dirigiu-se à organização do trabalho pedagógico não presencial, ao tempo de trabalho, às formas de envio das atividades e ao relacionamento com as famílias.

Desse modo, o questionário é do tipo interseccional, quando os dados são colhidos para descrever informações sobre uma população - os professores - em um dado momento, a pandemia (BABBIE, 2001). Para isso, o questionário elaborado passou por teste para verificação do seu potencial para captar as informações desejadas. Professores e pedagogos, num total de dez voluntários, foram convidados a colaborar nesta etapa. Estes sujeitos avaliaram e contribuíram para a formulação das questões.

Procurou-se garantir a confiabilidade e representatividade do público pesquisado. Pois a totalidade dos professores e pedagogos dos três NREs teve a possibilidade de participar. As respostas e os respondentes da pesquisa configuram-se como a amostragem.

A finalidade última do survey por amostragem é selecionar um conjunto de elementos de uma população de tal forma que descrições destes elementos (estatísticas) descrevam com precisão a população total da qual foram selecionadas. A amostragem probabilística fornece um método para ampliar a possibilidade de alcançar esta meta, bem como métodos para estimar o grau de sucesso provável. [...] A seleção aleatória é a chave deste processo. (BABBIE, 2001, p. 125)

Sendo assim, os resultados coletados foram armazenados eletronicamente pelo GESFORT e tratados estatisticamente por meio do software Excel. 


\subsection{A realidade sobre o trabalho docente na pandemia no Sudoeste do Paraná}

Nesta seção, apresentamos os dados coletados. A exposição segue a ordem do questionário: identificação, formação e trabalho; o trabalho docente remoto durante a pandemia - EaD; e o trabalho docente e organização do trabalho pedagógico.

\subsubsection{Identificação, formação e trabalho}

Nesta primeira etapa do questionário, buscamos caracterizar o grupo de profissionais que atuam nestes núcleos quanto a idade, sexo, tipo de contrato de trabalho e outras questões.

Todos os professores que atuam nos anos finais do Ensino Fundamental e Ensino Médio e os pedagogos dos NREs de Dois Vizinhos, Francisco Beltrão e Pato Branco foram convidados a responder à pesquisa. Neste momento, optamos pelo não envio do questionário aos diretores e demais profissionais das escolas, devido aos objetivos da pesquisa, que se direcionavam à ação docente - professores e pedagogos. Nestes três NREs, trabalham 4.224 profissionais, entre professores e pedagogos, conforme Tabela 1:

Tabela 1 - Total de professores e pedagogos por NRE

\begin{tabular}{l|cc}
\hline $\begin{array}{c}\text { Núcleos Regionais de } \\
\text { Educação }\end{array}$ & $\begin{array}{c}\text { Total de } \\
\text { profissionais }\end{array}$ & Percentual \\
\hline Dois Vizinhos & 621 & 14,7 \\
Francisco Beltrão & 1.816 & 43 \\
Pato Branco & 1.787 & 42,3 \\
Total & 4.224 & 100 \\
\hline
\end{tabular}

Fonte: Site Dia a Dia Educação.

Estes três NREs são responsáveis pelas instituições públicas dos anos finais do Ensino Fundamental e Ensino Médio de todos os municípios da região sudoeste do Paraná. Conforme o mapa abaixo: 
Figura 1 - Mapa das Regiões Geográficas Imediatas do Paraná

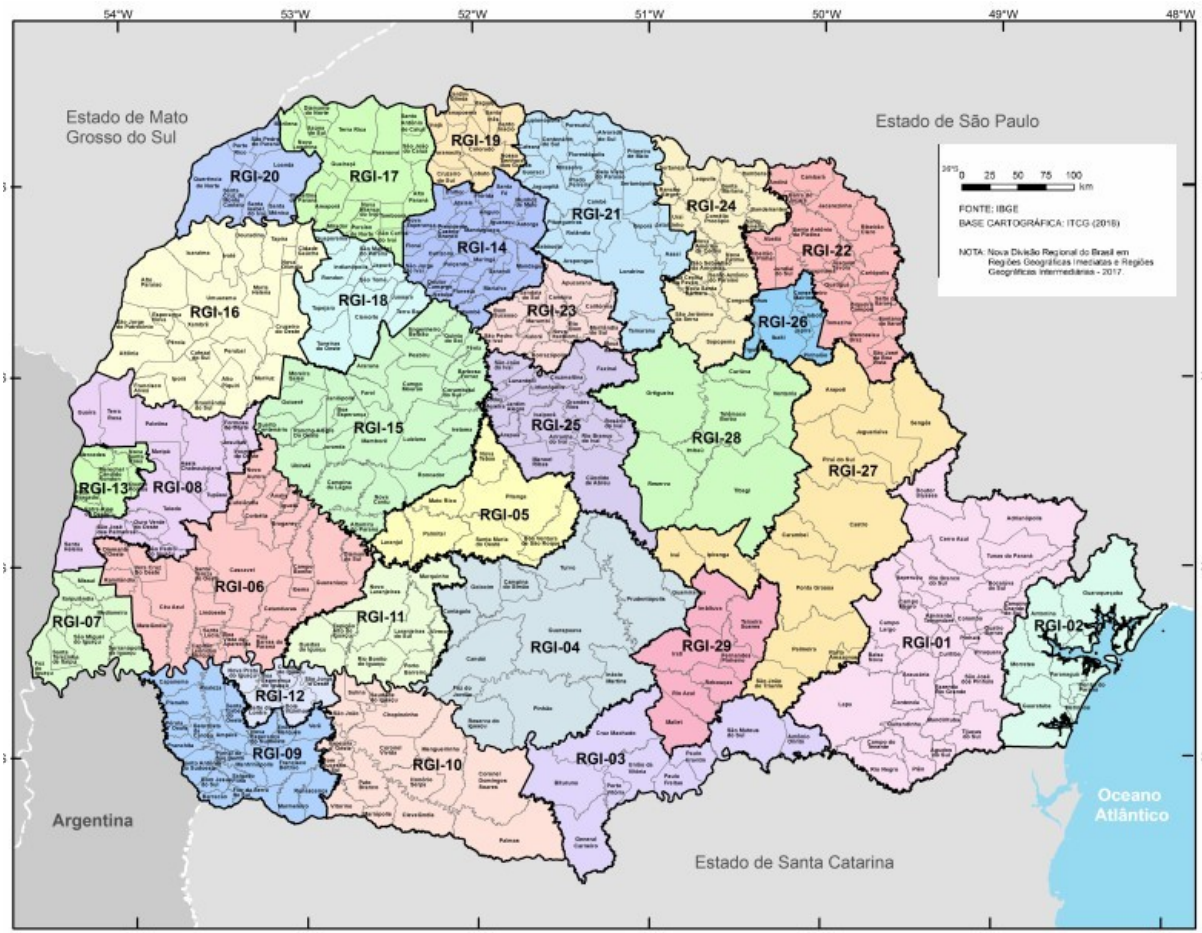

Fonte: IBGE. Base cartográfica: ITCG (2018)

A Região Geográfica Imediata (RGI) -12, compreende o NRE de Dois Vizinhos, a RGI -09, o NRE de Francisco Beltrão e a RGI -10, o NRE de Pato Branco. Essas três microrregiões do Paraná tem uma população estimada em 2018, pelo IBGE de 622.523 pessoas, divididas em 42 municípios. Ou seja, trata-se uma região abrangente, cuja maior parte dos municípios são de pequeno porte, sendo que quatorze, ou $33 \%$, contam com apenas um ou dois colégios estaduais, que ofertam os anos finais do Ensino Fundamental ou Médio.

Nestas três regionais, existem 350 instituições em que trabalha o público-alvo da pesquisa, distribuídos conforme a Tabela 2. 
Tabela 2 - Estabelecimentos educacionais do Ensino Fundamental e Médio da Rede Estadual

\begin{tabular}{|c|c|c|c|}
\hline \multirow[t]{2}{*}{ Tipo do estabelecimento de ensino } & \multicolumn{3}{|c|}{ Número de estabelecimentos } \\
\hline & $\begin{array}{c}\text { Dois } \\
\text { Vizinhos }\end{array}$ & $\begin{array}{l}\text { Francisco } \\
\text { Beltrão }\end{array}$ & $\begin{array}{l}\text { Pato } \\
\text { Branco }\end{array}$ \\
\hline Estabelecimentos de Ensino Fundamental & 28 & 88 & 67 \\
\hline Estabelecimentos de Ensino Médio & 13 & 46 & 52 \\
\hline $\begin{array}{l}\text { Estabelecimentos de Ensino com Educação } \\
\text { Profissional }\end{array}$ & 4 & 14 & 7 \\
\hline $\begin{array}{l}\text { Estabelecimentos de Ensino com Educação Especial } \\
\text { - Classes Exclusivas }\end{array}$ & - & - & 1 \\
\hline $\begin{array}{l}\text { Estabelecimentos de Ensino com Educação de Jo- } \\
\text { vens e Adultos (EJA) }\end{array}$ & 1 & 7 & 7 \\
\hline $\begin{array}{l}\text { Estabelecimentos de Ensino na EJA, no Ensino Mé- } \\
\text { dio }\end{array}$ & 1 & 7 & 7 \\
\hline Total & 47 & 162 & 141 \\
\hline
\end{tabular}

Fonte: IPARDES, 2020.

Há, no entanto, uma grande rotatividade na contratação dos profissionais, considerando os contratos temporários, admitidos por processo seletivo simplificado, cujo contrato é por tempo determinado. Dessa forma, consideramos, para essa pesquisa, os dados do mês de abril de 2020, como referência ao universo do público pesquisado.

Do total do público-alvo, 619 profissionais responderam à pesquisa, o que corresponde a $14,7 \%$ do total de professores e pedagogos dos NREs pesquisados, conforme Gráfico 1.

Gráfico 1 - Total de respondentes da pesquisa

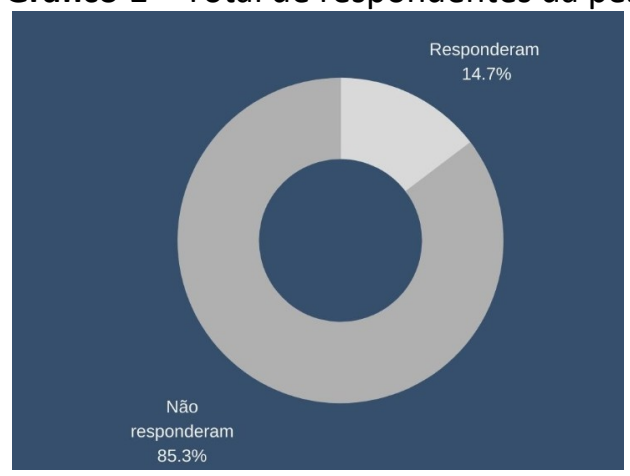

Fonte: Nossa autoria. 
Para Babbie (2001), o percentual de respondentes é significativo quando todo o público alvo teve igual oportunidade de responder à pesquisa. $\mathrm{O}$ que ocorreu neste caso. Nesse sentido, podemos afirmar que a amostra é significativa e apresenta resultados seguros para inferir sobre a situação da atuação docente nos três núcleos de educação pesquisados.

Os profissionais que responderam à pesquisa estão vinculados aos NREs conforme o Gráfico 2.

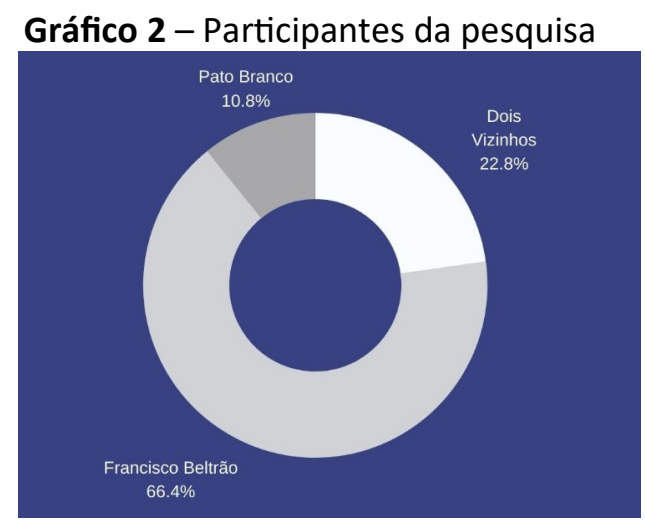

Fonte: Nossa autoria.

Entre os respondentes, $80 \%$ desempenham a função de professor, $15 \%$ de pedagogos e $5 \%$ são pedagogos e professores. 0 que se relaciona com o quantitativo destes profissionais nos colégios, que é composto, em média, por $87 \%$ de professores e $13 \%$ de pedagogos.

Figura 2 - Percentual de mulheres entre os respondentes

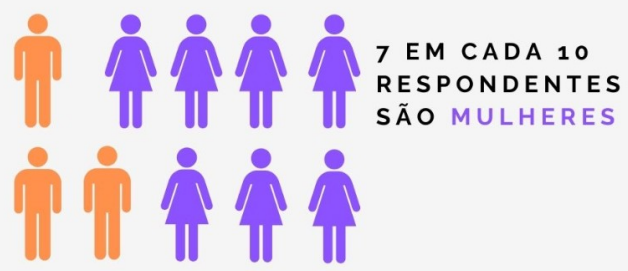

Fonte: Nossa autoria. 

mulheres.

O grupo que respondeu é predominantemente composto de

De acordo com o "Estudo exploratório sobre o professor brasileiro, com base nos resultados do Censo Escolar da Educação Básica 2007", do INEP (2009), o percentual brasileiro de mulheres no magistério é de $74,4 \%$ nos anos finais do Ensino Fundamental e de $64,4 \%$ do Ensino Médio. A amostra, portanto, segue o padrão nacional ${ }^{5}$.

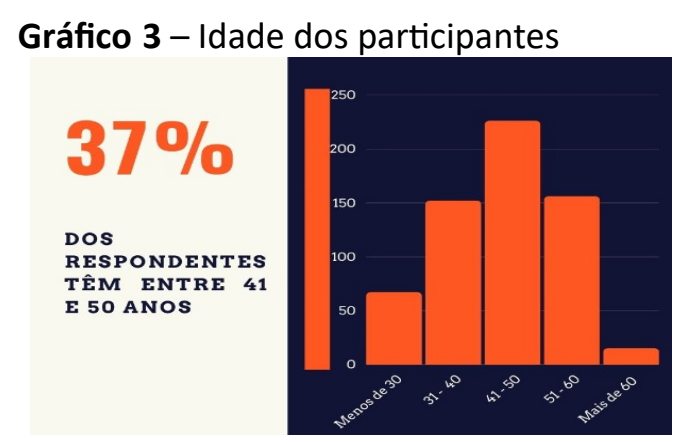

Fonte: Nossa autoria.

No grupo de respondentes, existes profissionais com menos de 30 anos e acima de 60. Destaca-se o grupo com a idade entre 41 e 50 anos. 0 percentual de respondentes do grupo de $31-40$ e 51-60 se equivale.

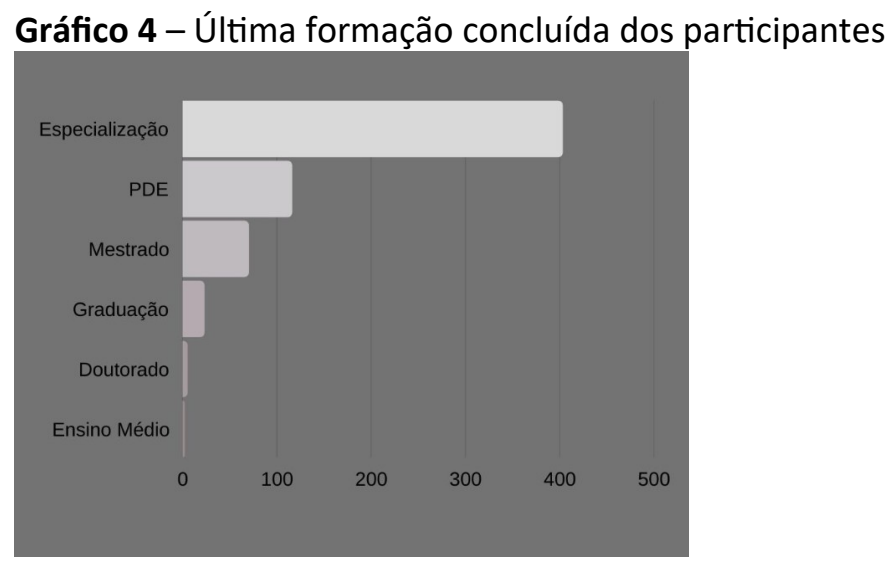

Fonte: Nossa autoria.

\footnotetext{
${ }^{5}$ Ver: AZEDO, M. L. N. de; OLIVEIRA, D. A.; VIERA, L. F. (2012) sobre trabalho docente na educação básica no Paraná, em que a profissão feminina é marcante.
} 
Quanto ao último nível de formação concluída, há desde o ensino médio até mestrado e doutorado. Entretanto, o grupo mais significativo é dos profissionais que concluíram especialização.

Também se destaca o quantitativo de professores que realizaram o Programa de Desenvolvimento da Educação (PDE), que é uma formação continuada no estado do Paraná. Destaca-se que o profissional formado em Ensino Médio tem vínculo de estágio ${ }^{6}$.

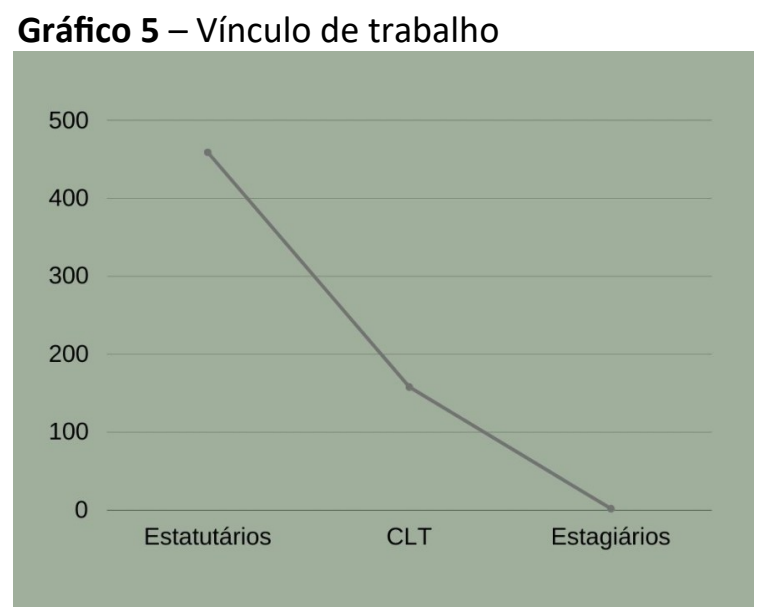

Fonte: Nossa autoria.

Quanto aos contratos de trabalho, entre os respondentes há docentes e pedagogos concursados, outros em contrato temporário e estagiários. O maior grupo de respondentes é de profissionais concursados, sob regime estatutário. A grande variação de contrato de professores está entre os temporários.

A legislação paranaense permite a contratação de professores e pedagogos sob regime especial (temporários) na rede estadual, por prazo determinado, via Processo Seletivo Simplificado (PSS), conforme dispõe a Lei Complementar Estadual n.o 108/2005:

Art. 10. Para atender à necessidade temporária de excepcional interesse público, os órgãos da Administração Direta e Autarquias do Poder Executivo poderão efetuar contratação de pessoal por tempo determinado, nas condições, prazos e regime especial previstos nesta

\footnotetext{
${ }^{6}$ Conforme Lei Federal n. $11.788 / 2008$ e Decreto Estadual n.o 8654/2010, revogado pelo Decreto Estadual n. 0 5283/2020.
} 
lei. Parágrafo único. As contratações a que se referem o caput deste artigo dar-se-ão sob a forma de contrato de regime especial. (PARANÁ, 2005, Art. 1ㅇ)

O contrato temporário não se enquadra no regime estatutário e não é atribuído nenhum vínculo empregatício.

Um total de 49,27\% dos respondentes fez sua primeira graduação em instituição privada, de maneira presencial. Esses dados acompanham a tendência nacional, em que a maioria dos professores tem formação em instituições privadas. $O$ ensino a distância é pouco representativo entre os respondentes. Apenas 2,59\% cursaram sua graduação nessa modalidade educacional. Este dado pode explicar o que se vê adiante, de pouco contato e experiência (formativa e profissional) com plataformas educacionais entre os respondentes.

A carga horária de trabalho dos profissionais varia de acordo com a forma de contrato. As predominantes são de 40 e 20 horas semanais.

Para 30\% dos respondentes, a carga horária semanal é de 40 horas, seguida de profissionais com 20 horas semanais, num total de $24,56 \%$. Embora tenham sido auferidas variadas cargas horárias semanais, em decorrência de especificidades, de acordo com o Gráfico 6:

Gráfico 6 - Carga horária semanal

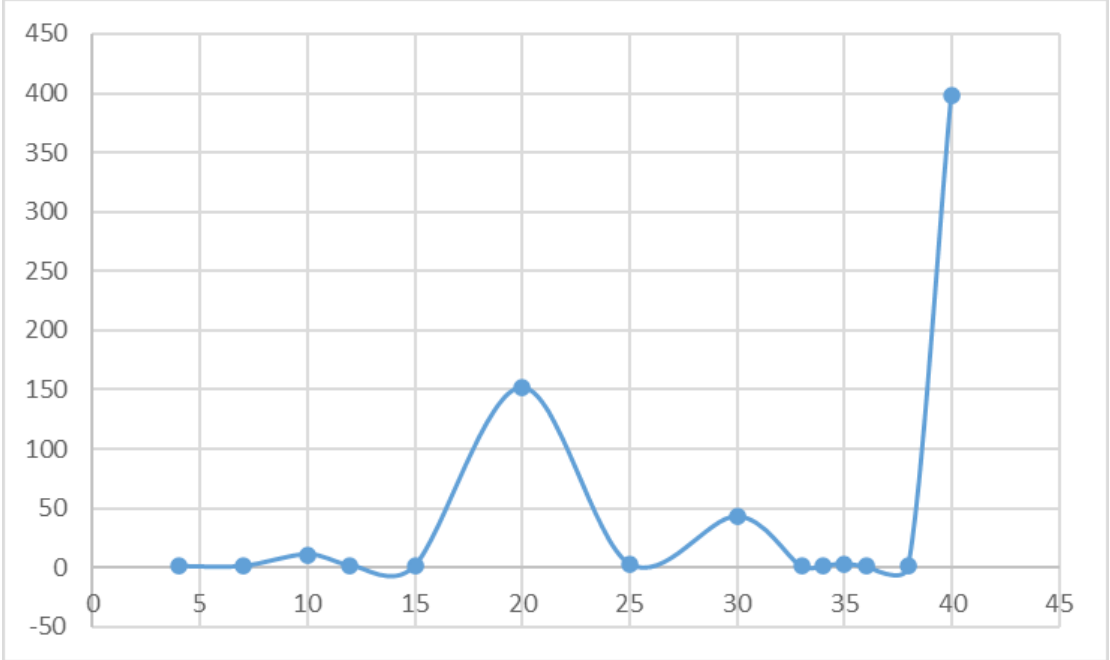

Fonte: Nossa autoria. 
A realidade de trabalhar em mais de uma escola é comum para 50\% dos professores entrevistados, assim como a realidade de atender muitas turmas. Embora a quantidade de turmas atendidas pelos professores seja bastante variada, destacamos que $42 \%$ dos respondentes atendem 10 ou mais turmas, de acordo com o Gráfico 7.

Gráfico 7 - Turmas atendidas por professor

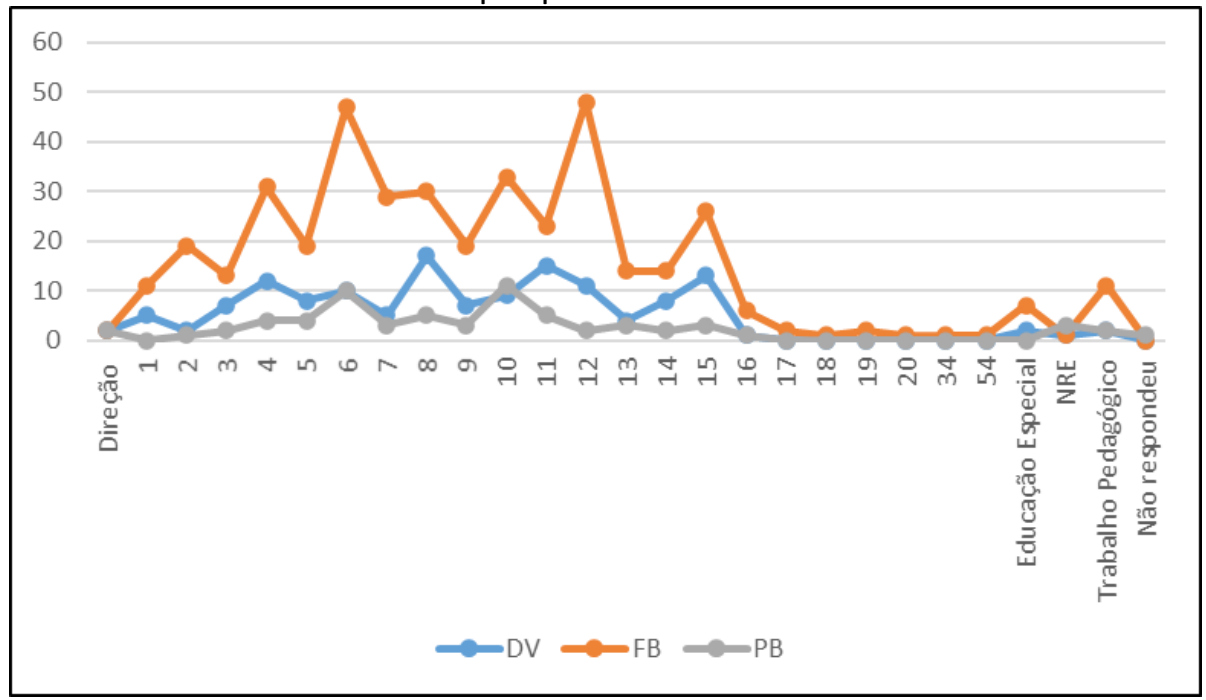

Fonte: Nossa autoria.

A quantidade de turmas atendidas, para a metade dos respondentes, se espalha em mais de uma escola. No Gráfico 8, observamos que, para um grupo significativo de $14,7 \%$ dos profissionais, a realidade do trabalho em múltiplas escolas (de 3 a mais de 5) é uma difícil situação a se enfrentar cotidianamente. Ela envolve o deslocamento entre as unidades, a adaptação e o respeito à realidade particular de cada escola. Agrega-se a isso a dificuldade do estabelecimento de relações cotidianas com o grupo escolar e o acompanhamento efetivo da proposta pedagógica. 
Gráfico 8 - Número de escolas de trabalho

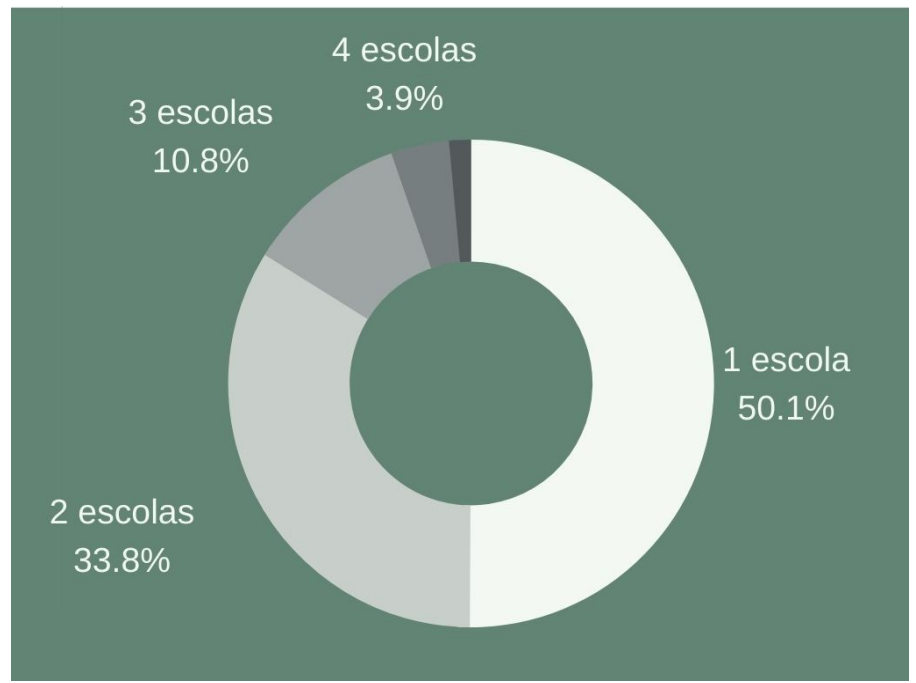

Fonte: Nossa autoria.

Embora o número de escolas e turmas atendidas seja alto $(42 \%$ atendem 10 turmas ou mais, e 50\% trabalha em mais de uma escola), a maior parte dos profissionais, cerca de $60 \%$, trabalha com 1 ou 2 disciplinas. Situação diferente dos pedagogos, que desenvolvem o trabalho pedagógico direcionado a todas as turmas de uma escola, cujo número de turmas atendidas varia de acordo com a organização interna e quantidade de matrículas e trabalhadores (docente e técnicos) da escola.

Desta forma, podemos considerar que por volta de $50 \%$ dos respondentes atuam em uma mesma escola, com uma ou duas disciplinas. Porém, o número de turmas e, portanto, de estudantes atendidos é alto e demandou do pedagogo e docentes uma organização em aspectos de comunicação exaustiva no cenário de pandemia.

\subsubsection{O trabalho docente remoto durante a pandemia - EaD}

Na segunda seção do questionário, buscamos identificar as particularidades e condições de realização do trabalho docente durante a pandemia. Nesse período, requisitou-se dos professores a utilização de meios tecnológicos para o envio de atividades e realização de aulas, além da prepara- 
ção de atividades de forma impressa destinada aos estudantes que não possuíam condições de recebê-las por meios digitais.

A quantidade de turmas atendidas, disciplinas e locais de trabalho afetaram de forma diferente cada profissional. Para muitos, a principal consequência do trabalho docente não presencial foi o aumento no tempo de trabalho em comparação às atividades presenciais. Possivelmente isso se deveu às adaptações necessárias no planejamento e formas de realização do trabalho docente, necessidade de atendimento individualizado às famílias, entre outros fatores.

Assim, o grande número de turmas impactou no aumento das horas de trabalho, o que foi destacado por $82,71 \%$ dos participantes (Tabela 3 ). Essa consequência foi mais percebida por mulheres. Constatamos que $84 \%$ delas relataram aumentar o tempo de trabalho, contra $77 \%$ dos homens.

Esse aumento de tempo de trabalho se deve, potencialmente, ao fato de que $54 \%$ dos professores afirmarem que prepararam atividades específicas para cada turma, em razão das especificidades e poucos $(0,8 \%)$ utilizam as atividades disponibilizadas pela SEED. Foi preciso mais tempo atribuído para preparação, reflexão e inclusão do conteúdo e atividades nas plataformas, também, conforme já salientado, pelas diversas metodologias adotadas pelos docentes de forma a atender todos os estudantes.

Tabela 3 - Necessidade de ajuste na carga horária

\begin{tabular}{l|cc}
\hline & $\begin{array}{c}\text { Participan- } \\
\text { tes }\end{array}$ & $\%$ \\
\hline Fiz ajustes parciais no tempo trabalho. & 50 & 8,08 \\
Não, trabalho nos mesmos horários e tempo & 20 & 3,23 \\
$\begin{array}{l}\text { que trabalhava na escola. } \\
\text { Sim, tive que ajustar meu horário, aumentou a }\end{array}$ & 512 & 82,71 \\
$\begin{array}{l}\text { tempo de trabalho. } \\
\text { Sim, tive que ajustar meu horário, mantendo o }\end{array}$ & 37 & 5,98 \\
$\begin{array}{l}\text { mesmo tempo de trabalho. } \\
\text { Total }\end{array}$ & 619 & 100,00 \\
\hline
\end{tabular}

Fonte: Nossa autoria. 
Aproximadamente 50 profissionais se posicionaram na questão aberta, apontando o aumento excessivo do tempo de trabalho. Uma professora se posicionou da seguinte forma:

"Trabalho excessivo em função de maior tempo destinado só trabalho, pois agora trabalho nos 3 períodos pra dar conta. Não sabia acessar essa plataforma, isso causou grande estresse, pois tinha que trabalhar e aprender ao mesmo tempo sobre o que precisava enviar. Muita cobrança da escola com muitas mensagens e lives, resoluções pra entender. Muitas mensagens dos colegas desesperados. Todo mundo precisando se ajudar pra dominar a plataforma e poder trabalhar. Quanto aos alunos, eles estão sendo classificados por quem acessa e quem não acessa. A questão da aprendizagem não existe. Além dos alunos que nunca acessaram que serão excluídos do processo, não haverá aprendizagem." (Professora NRE - PB)

Apenas 3\% dos respondentes afirmaram seguir trabalhando o mesmo número de horas que desenvolvia regularmente na escola, sem necessidade de fazer ajustes nos horários de trabalho.

Houve uma mudança expressiva na organização da jornada de trabalho dos docentes e pedagogos. $\mathrm{O}$ excesso de atividades ultrapassou o período diário ou noturno de contratação.

Com as aulas sendo desenvolvidas de forma não presencial, foi fundamental o uso da internet. Esse recurso não foi disponibilizado pelo governo paranaense aos professores. Cerca de $95 \%$ dos respondentes afirmaram arcar com os custos desse recurso. 0 mesmo acontece com os equipamentos utilizados, que também são particulares em $93 \%$ dos casos. Apenas $4,9 \%$ dos respondentes utilizam equipamentos que foram emprestados pelo colégio ou fornecidos pelo estado.

No Gráfico 9, observamos que mais de um equipamento, geralmente pessoal, foi utilizado para garantir a continuidade do serviço educacional. Destaca-se o uso de celulares e notebooks. 
Gráfico 9 - Equipamentos utilizados

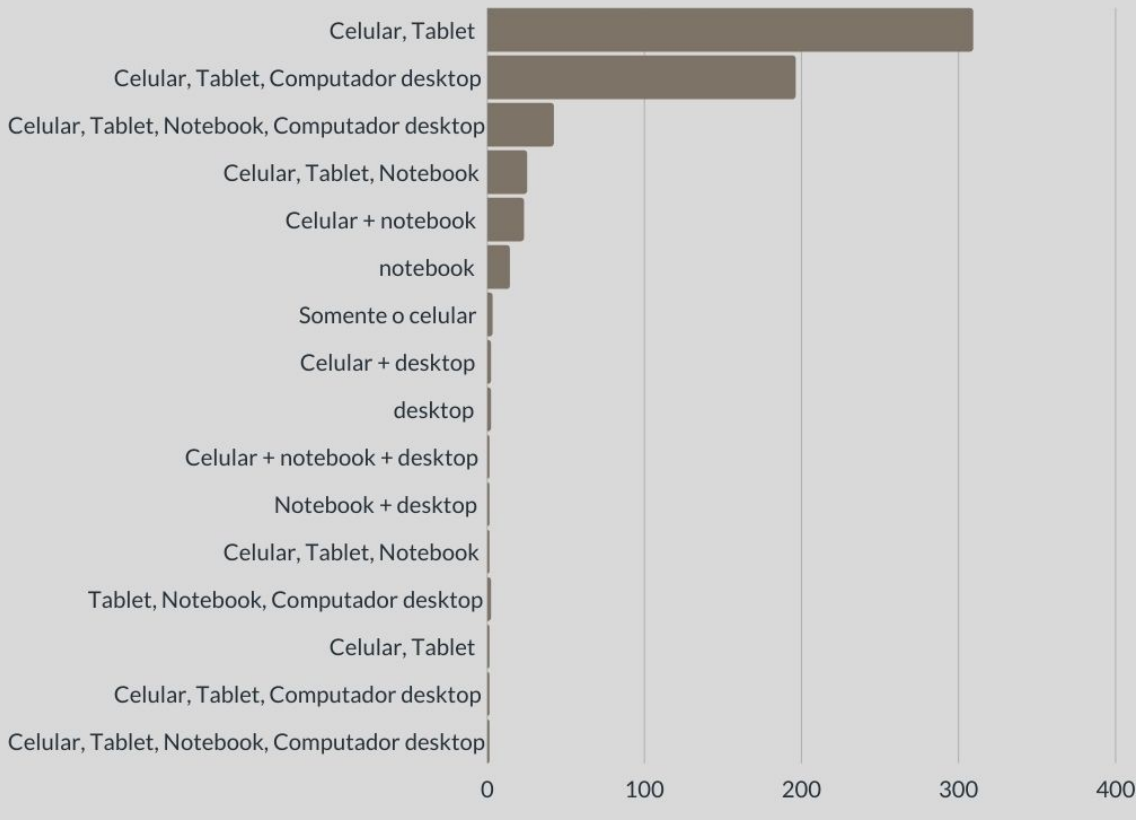

Fonte: Nossa autoria.

No grupo familiar de $37,48 \%$ dos profissionais, estes são os únicos envolvidos no trabalho remoto. Entretanto, a maior parte $(62,52 \%)$ possui ainda duas ou mais pessoas em casa realizando trabalho remoto. Essa situação assevera a problemática da posse de equipamentos e acesso à internet.

Um percentual significativo $(21,8 \%)$ dos professores, conforme Gráfico 10, afirma não ter equipamentos disponíveis para todos os membros da família que necessitam para o trabalho remoto. $O$ que tornou necessário fazer ajustes no tempo de utilização para que todos do grupo familiar pudessem desempenhar suas atividades. 
Gráfico 10 - Profissionais que têm equipamento disponível para todo grupo familiar

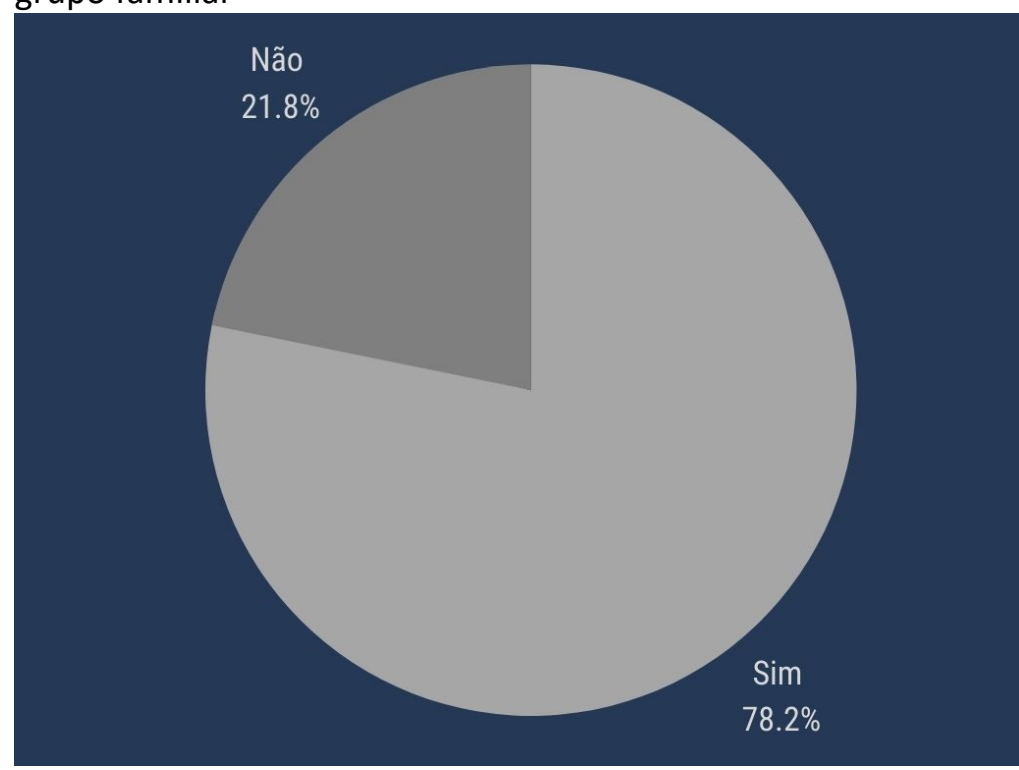

Fonte: Nossa autoria.

Desta forma, podemos afirmar que os professores e pedagogos utilizaram seus recursos particulares, com equipamento e custo com internet, em muitos casos, compartilharam os equipamentos com outros membros do grupo familiar, para garantir a continuidade da oferta do serviço público de educação do estado do Paraná.

Uma dificuldade no trabalho não presencial foi o uso de plataformas educacionais. Apenas $12 \%$ afirmaram que já tinham experiência na utilização destes recursos. Quase a metade dos participantes (48\%) afirmaram nunca ter feito uso, e $40 \%$ já haviam utilizado, porém não se sentiam seguros com as plataformas educacionais para desempenhar sua atividade de ensino, conforme o Gráfico 11.

Constatamos que a maior parte dos profissionais não se sentia em condições de iniciar as atividades docentes mediadas por plataformas ou recursos computacionais e, mesmo assim, em curto espaço de tempo tiveram que se adaptar. Possivelmente essa adaptação também tenha sido um fator do aumento da carga horária de trabalho. 
Gráfico 11 - Situação em relação ao uso de plataformas educacionais

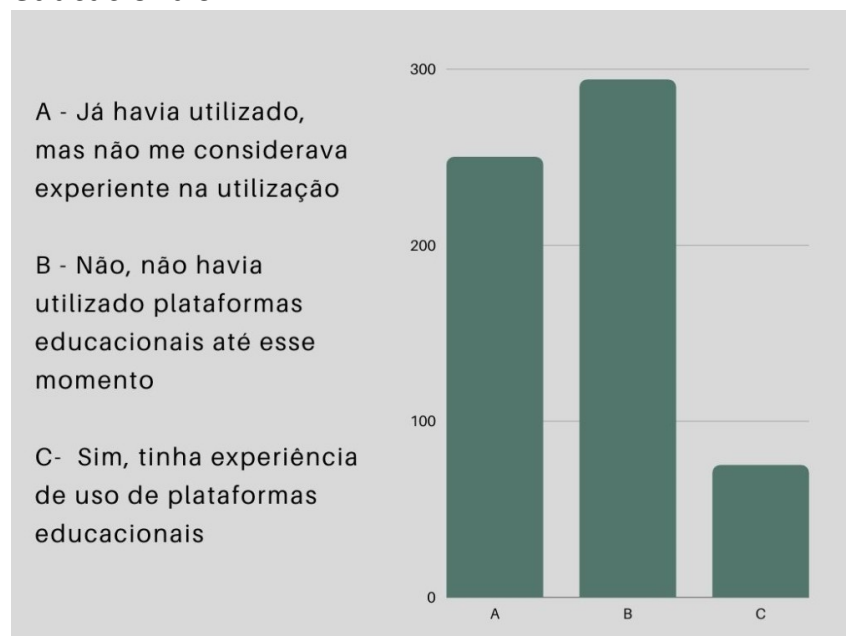

Fonte: Nossa autoria.

Estes dados têm pouca variação quando observamos a idade dos participantes. Ou seja, não constatamos mais conhecimento ou uso de plataformas educacionais entre os participantes mais jovens. Entretanto, quando observamos o sexo, verificamos que, entre os participantes do sexo masculino, há um maior conhecimentos sobre as plataformas educacionais, como podemos ver na Tabela 4:

Tabela 4 - Comparação do conhecimento sobre as plataformas educacionais

\begin{tabular}{l|cccc}
\hline & $\begin{array}{c}\text { Até 30 } \\
\text { anos }\end{array}$ & $\begin{array}{c}\text { Entre 41 e } \\
51 \text { anos }\end{array}$ & Feminino & Masculino \\
\hline $\begin{array}{l}\text { Já havia utilizado, mas não } \\
\text { me considerava experiente } \\
\text { na utilização. }\end{array}$ & 35,3 & 42,42 & 42,14 & 28,09 \\
$\begin{array}{l}\text { Não, não havia utilizado pla- } \\
\text { taformas educacionais até }\end{array}$ & 57,35 & 45,46 & 47 & 52,81 \\
$\begin{array}{l}\text { esse momento. } \\
\text { Sim, tinha experiência de uso } \\
\text { de plataformas educacionais. }\end{array}$ & 7,35 & 12,12 & 10,86 & 19,1 \\
Total & 100 & 100 & 100 & 100 \\
\hline
\end{tabular}

Fonte: Nossa autoria. 
Embora a aprendizagem sobre o uso das plataformas tenha sido fator de estresse sentido por muitos professores, houve aqueles que viram nesse processo uma positividade, o que foi destacado como um aspecto positivo desse tempo:

"A família ver que ser professor não é fácil, e o aprendizado do uso das tecnologias." (Professora NRE - DV)

"Aprendizado. Tenho aprendido muito com a plataforma, coisas que poderemos utilizar pós pandemia." (Professora NRE - DV)

"Aprender novas ferramentas, repensar as metodologias necessárias para aprendizagem, a evidência dos profissionais que buscam realmente a formação contínua." (Professora NRE - FB)

"Aprendi a gravar vídeos, fiquei mais próxima do meu filho que é quem me ajuda a gravar os vídeos, ele também tem aula on-line, faz Direito, e está sempre pronto pra me auxiliar." (Professora NRE - PB)

Quando se trata do trabalho docente realizado no domicílio do professor com a utilização de recursos tecnológicos, requer-se um espaço, na residência, adequado a essa atividade. A maior parte dos professores afirmou não ter esse espaço físico adequado em casa para realizar as atividades on-line e, ainda, compartilha o espaço com outros membros da família. Entre os que têm um espaço exclusivo para seu uso, eles afirmam que este não é adequado pra a realização das atividades. Apenas $24,72 \%$ dos professores afirmaram possuir um espaço adequado para seu trabalho em casa, de acordo com a Tabela 5.

Tabela 5 - Espaço adequado na residência do professor

\begin{tabular}{l|cc}
\hline & Participantes & $\%$ \\
\hline $\begin{array}{l}\text { NÃO, compartilho espaços em casa com ou- } \\
\text { tras pessoas. }\end{array}$ & 354 & 57,19 \\
$\begin{array}{l}\text { SIM, possuo um local exclusivo para meu tra- } \\
\text { balho. }\end{array}$ & 153 & 24,72 \\
$\begin{array}{l}\text { TENHO um local exclusivo, porém não é ade- } \\
\text { quado. }\end{array}$ & 112 & 18,09 \\
Total & 619 & 100,00 \\
\hline
\end{tabular}

Fonte: Nossa autoria.

Desta forma, somente $1 / 4$ (um quarto) aproximadamente dos professores tem espaço adequado em casa. Da mesma forma, 1/4 (um quarto) 
não possui equipamento disponível em sua residência para o desempenho das atividades letivas.

Mesmo a maioria não tendo conhecimento adequado sobre plataformas educacionais ou outros recursos computacionais, os profissionais utilizaram mais de um recurso simultaneamente. Alguns deles, recomendadas oficialmente pela SEED, outras, por necessidade de comunicação.

Cerca de $38 \%$ dos participantes utiliza 5 ou mais plataformas para o envio de atividades. As mais utilizadas são Google Classroom, WhatsApp, Email, YouTube, Aplicativo Aula Paraná, conforme a Tabela 6:

Tabela 6 - Plataformas e aplicativos utilizados

\begin{tabular}{l|ccccc}
\hline & $D V$ & $F B$ & $P B$ & $\begin{array}{c}\text { Total de } \\
\text { participan- } \\
\text { tes }\end{array}$ & $\begin{array}{c}\text { \% de participan- } \\
\text { tes que usam a } \\
\text { plataforma }\end{array}$ \\
\hline Google Classroom & 133 & 378 & 60 & 571 & 92,25 \\
WhatsApp & 126 & 366 & 62 & 554 & 89,50 \\
Aplicativo Aula Paraná & 95 & 256 & 38 & 389 & 62,84 \\
YouTube & 87 & 272 & 40 & 399 & 64,46 \\
E-mail & 84 & 281 & 44 & 409 & 66,07 \\
TV aberta & 15 & 47 & 13 & 75 & 12,12 \\
Atividades Impressa & 5 & 6 & 3 & 14 & 2,26 \\
Google Meet & 3 & 6 & 3 & 12 & 1,94 \\
Telefone & 2 & 2 & 0 & 4 & 0,65 \\
Facebook & 2 & 2 & 0 & 4 & 0,65 \\
Instagram & 1 & 0 & 0 & 1 & 0,16 \\
\hline Fonte: & & & & &
\end{tabular}

Fonte: Nossa autoria.

Esta necessidade exigiu adaptação e estudo para a utilização destas plataformas. Mesmo assim, os profissionais enfrentam problemas na comunicação e realização das atividades pelos estudantes. É o que vemos no relato abaixo reproduzido:

"É muito desgastante, sinto falta do contato com os alunos. Tenho dificuldade em criar as atividades no Classroom. Os alunos têm dificuldade de abrir as atividades. Respondo pais e alunos a todo momento. Aprendizagem será muito excludente. 50\% ou mais dos meus alunos não tem acesso às plataformas digitais." (Professor do NRE de FB) 
Pelos dados obtidos, constatamos que os profissionais buscaram alternativas para dar continuidade ao processo educativo, mesmo com limitações de conhecimento, de espaço na residência e outros problemas.

\subsubsection{O trabalho docente e organização do trabalho pedagógico}

Na terceira seção do questionário, buscamos identificar as questões pedagógicas, se houve necessidade de adaptação do plano de trabalho docente, se isso implicou na alteração do tempo de trabalho e se houve necessidade diferenciada de comunicação com a família.

Em razão do pouco contato com as plataformas educacionais, relatada pelos participantes, cerca de $90,63 \%$ afirmaram utilizar mais tempo para preparar as atividades para serem encaminhadas aos alunos durante a pandemia, do que utilizavam para preparar as atividades para as aulas presenciais. Apenas $8,24 \%$ afirmam utilizar o mesmo tempo, índice que é menor do que os $12 \%$ que afirmaram dominar com segurança o uso dos novos recursos.

Além de preparar, disponibilizar e acompanhar o desenvolvimento das atividades de modo não presencial pelos estudantes, foi necessário que os professores e pedagogos também atendessem às famílias de forma diferenciada, do que em relação ao período de atividades presenciais. Isso decorreu da dificuldade de acesso, ou do uso dos recursos tecnológicos, entre outros motivos, conforme a Tabela 7:

Tabela 7 - Motivo do contato dos profissionais com as famílias

\begin{tabular}{l|cc}
\hline \multicolumn{1}{c|}{ Motivos } & Menções & $\begin{array}{c}\text { \% dos participantes } \\
\text { que alegam o } \\
\text { motivo }\end{array}$ \\
\hline Para tirar dúvidas gerais. & 398 & 64,30 \\
Para acompanhar o processo de & 335 & 54,12 \\
aprendizagem. & 327 & 52,83 \\
Por dificuldades de acesso aos conteúdos. & 300 & 48,47 \\
Por falta de atividade dos estudantes. & 77 & 12,44 \\
Não mantenho contato com familiares de & & 0,32 \\
estudantes. & 2 & \\
Ajudar a responder as atividades. & & \\
\hline
\end{tabular}

Fonte: Nossa autoria. 
Observamos que mais de $80 \%$ dos participantes se envolveram, de alguma forma, neste atendimento às famílias. Sanar dúvidas gerais, nas quais se incluem o uso das plataformas, forma de acesso, entrega de atividades, entre outros, foi o que mais demandou atenção dos profissionais no atendimento às famílias.

Para o contato com as famílias e para a disponibilização de atividades, muitas plataformas e aplicativos foram utilizados. Novamente, na maior parte dos casos, aproximadamente $60 \%$, mais de um recurso foi utilizado. Os mais utilizados estão apresentados no Gráfico 12:

Gráfico 12 - Meios utilizados para contato com as famílias

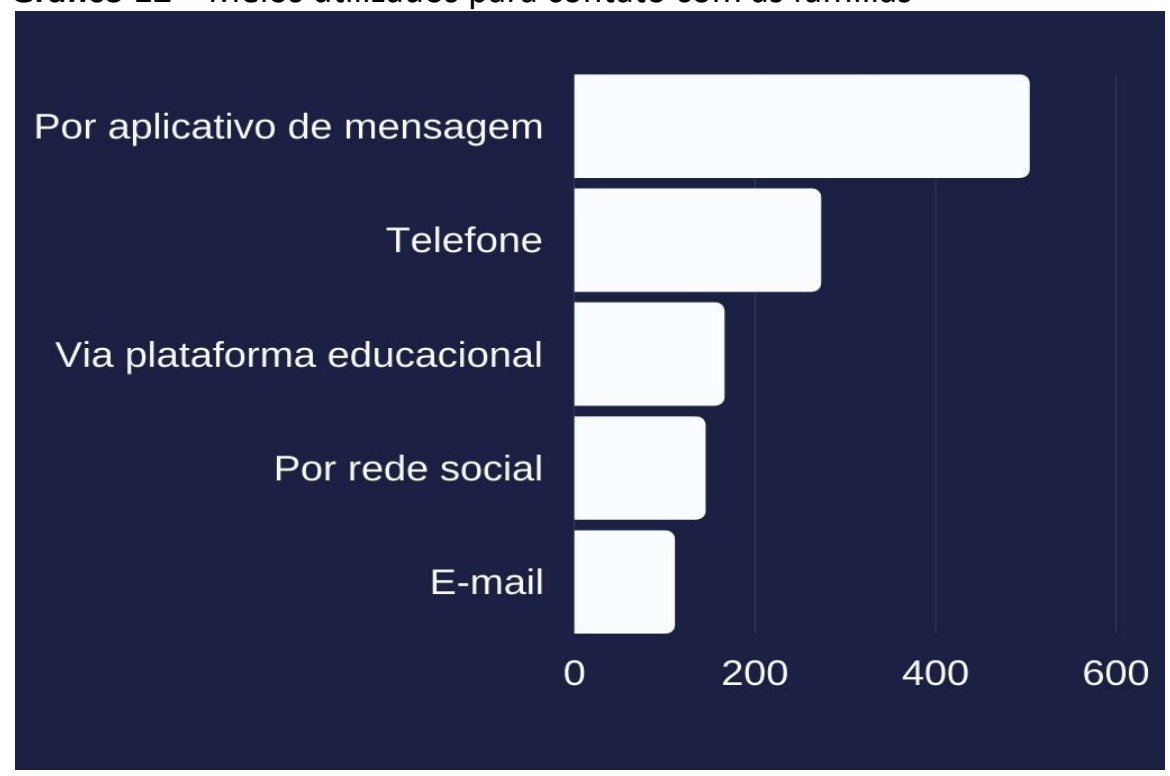

Fonte: Nossa autoria.

Essa necessidade de constante contato com estudantes e familiares implicou em um acréscimo de tarefas, além das desenvolvidas para os fins letivos, acarretando, consequentemente, um aumento de trabalho e demanda aos profissionais. Estes eram procurados pelas famílias para solucionar todos os tipos de problema, inclusive os que não dependiam da atuação do professor. É o que relata uma professora do NRE de Dois Vizinhos:

"A minoria dos alunos estão fazendo as atividades pelo aplicativo; perde-se muito tempo explicando em particular como pode entregar 
os trabalhos; pais estressados reclamando da quantidade de atividades e tempo de aula; não tenho mais tempo para mim porque tenho 15 turmas no WhatsApp... corpo e cabeça cansados!!!" (Professora NRE- DV)

Para $70 \%$ dos participantes, houve aumento do tempo de comunicação com a família durante a pandemia, em comparação ao período de aulas presenciais.

Nas duas questões abertas, os profissionais apontaram o que viram de positivo na forma com as atividades letivas seguiram durante a pandemia e também o que foi mais problemática. $O$ que professores e pedagogos apontaram como positivos e negativos do período letivo durante a pandemia pode ser sintetizado no Quadro 2:

Quadro 2 - Pontos positivos e negativos apontados pelos professores sobre o trabalho durante a pandemia

\begin{tabular}{|l|l|}
\hline Aspectos problemáticos & $>$ excesso de trabalho; \\
& $>$ problemas de saúde, dores musculares, dores de \\
& $>$ excesso de tempo frente às telas; \\
$>$ & dificuldade de acesso por parte dos estudantes; \\
$>$ & ineficiência do processo de ensino; \\
$>$ & estresse causado pelas dúvidas e incertezas \\
& desse período; \\
$>$ & dificuldade para resolver os problemas que \\
& surgiram, falta de suporte técnico e pedagógico; \\
$>$ & dificuldade em utilizar as plataformas \\
& educacionais; \\
$>$ & necessidade de utilização de múltiplas \\
& ferramentas concomitantes; \\
$>$ & horário de trabalho indefinido; \\
$>$ & percepção de poucos resultados acadêmicos dos \\
& estudantes; \\
$>$ & falta de informação sobre os programas, \\
& aplicativos e plataformas e falta preparação para \\
utilizá-las; & $>$ menos tempo disponível para assuntos pessoais; \\
$>$ & dificuldade para ter retorno das atividades dos \\
estudantes; & $>$ muito trabalho para correção de atividades \\
copiadas da internet;
\end{tabular}




\begin{tabular}{|c|c|}
\hline & $\begin{array}{l}>\text { não conseguir atingir todos os estudantes; } \\
\text { os estudantes não têm uma participação efetiva; } \\
\text { problemas oriundos da desigualdade social, } \\
\text { estudantes que não possuem os recursos } \\
\text { tecnológicos necessários para acompanhar as } \\
\text { aulas; } \\
\text { cansativo, exaustivo, desgastante mentalmente e } \\
\text { psicologicamente. Entre outras problemáticas. }\end{array}$ \\
\hline Aspectos positivos & $\begin{array}{l}\text { possibilidade de manter o cuidado com a saúde, } \\
\text { em relação a pandemia; } \\
>\text { possibilidade de aprendizagem colaborativa; } \\
\text { aprendizagem em relação às tecnologias, } \\
\text { plataformas e aplicativos educacionais; } \\
\text { reorganização de rotina de trabalho, } \\
\text { crescimento pessoal no que concerne à } \\
\text { metodologias ativas; } \\
>\text { ajudar os estudantes a utilizarem a plataforma; } \\
\text { maior apropriação com as famílias, maior } \\
\text { cooperação entre colegas. }\end{array}$ \\
\hline
\end{tabular}

Fonte: Nossa autoria.

Nesse sentido, o posicionamento de um profissional agrega esses pontos:

"Como é uma situação nova para todos, estamos lutando para que os alunos não percam tudo. O legal é que todos estão se esforçando e fazendo o possível para que não percam muito. É uma nova experiência, onde não medimos esforços para que esta perca seja branda." (Professora NRE-FB)

Como uma situação nova e inesperada, observamos que o estresse provocado pela pandemia, em razão de muitos profissionais serem do grupo de risco, ou terem familiares nessa condição, somou-se ao estresse de enfrentar um trabalho de tipo novo, que exigiu rápida adaptação de professores, pedagogos, famílias e estudantes.

É possível afirmar que houve um aumento da demanda, de adequação de espaço e tempo de trabalho e que houve uma busca por solucionar os desafios da comunicação com os estudantes, considerando o grande número de recursos utilizados pelos professores. 


\section{CONCLUSÕES}

A situação da pandemia trouxe mudanças expressivas no desempenho das atividades docentes na Rede Estadual de Educação, provocando o aumento da carga horária de trabalho dos professores e pedagogos. A mesma situação exigiu aprendizagens dos recursos tecnológicos de comunicação em um curto espaço de tempo, além de reorganização do espaço privado da casa, estando adequado para o desempenho das atividades de ensino remoto.

Os professores, em sua maioria, estão utilizando seus próprios meios tecnológicos - internet e equipamentos - para continuar o processo de ensino e aprendizagem dos estudantes.

Percebemos o comprometimento e o engajamento destes profissionais com a educação, na medida em que se desdobram com o uso simultâneo de inúmeras plataformas para o envio de atividades e para a comunicação com as famílias. Eles e elas realizam atividades de orientação de uso dos equipamentos, estimulam os estudantes a se manterem engajados com sua aprendizagem e acompanham o desenvolvimento desse processo nessas condições tão novas e adversas.

Certamente, esse período deixará marcas indeléveis em professores e estudantes. Se, por um lado, o momento vivido provocou aprendizagens quanto ao uso das tecnologias de comunicação, ele provocou também a saudade do contato físico e presencial de professores e estudantes em sala de aula.

O ensino híbrido tem sido um dos caminhos adotados pelo sistema de educação, internacional e nacionalmente, como uma forma de organização e método de ensino das atividades letivas para a continuidade do trabaIho educacional. Esse método se caracteriza por mesclar dois modelos de aprendizagem: o presencial e o on-line (EaD).

Esperamos que com a divulgação dos resultados desta pesquisa possamos discutir coletivamente as mudanças no trabalho escolar, a percepção acerca da educação nesse formato de ensino remoto e o encaminhamento do ensino híbrido. Com estas ações, poderemos aprofundar o real sentido em que o cenário pandêmico coloca como questões a serem enfrentadas pelos trabalhadores da educação, e compreensão do sentido do trabalho docente e formação das crianças e juventude. O cenário que vivemos tem afetado consideravelmente os profissionais da educação, com a 
retirada de direitos e condições de trabalho que possam manter uma qualidade essencial no processo educacional.

Os dados também colocam como necessidade a continuidade da mobilização dos docentes na defesa da escola pública, gratuita e presencial. 


\section{REFERÊNCIAS}

AGUIAR, M. A. S. impactos da pandemia da covid-19 na educação brasileira e seus reflexos nas políticas e orientações curriculares. Revista de Estudos Curriculares, v. 11, n. 1, 2020.

ANTUNES, R. O vilipêndio do coronavírus e o imperativo de reinventar o mundo. In: TOSTES, A.; MELO FILHO, H. (orgs.) Quarentena: reflexões sobre a pandemia e depois. Bauru: Projeto Editorial Práxis e Canal 6, 2020.

APP. APP-Sindicato cobra posicionamento do Conselho de Educação sobre ensino a distância, 2020. Site APP, Curitiba, 2 junho 2020. Disponível em: https://bit.ly/3uVUgd0. Acesso em: 1 out. 2020.

AZEVEDO, Mário Luiz Neves de; OLIVEIRA, Dalila Andrade; VIEIRA, Lívia Fraga. $O$ trabalho docente na educação básica no Paraná. Belo Horizonte, MG: Fino Traço, 2012.

BABBIE, Earl. Métodos de pesquisa de survey. Belo Horizonte: Ed UFMG, 2001.

BRASIL. Lei n.o 11.788. Diário Oficial da União, Brasília, 26 set. 2008.

COLEMARX. Coletivo de Estudos em Marxismo e Educação. Em defesa da educação pública comprometida com a igualdade social: porque os trabaIhadores não devem aceitar aulas remotas. Rio de Janeiro, 2020.

CORONAVÍRUS BRASIL. Disponível em: https://bit.ly/3uV0zO5. Acesso em: 16 out. 2020.

HARVEY, D. Política anticapitalista em tempos de covid-19. In: DAVIS, M. et al. Coronavírus e a luta de classes. Brasil: Terra sem Amos, 2020.

INEP. Estudo exploratório sobre o professor brasileiro com base nos resultados do Censo Escolar da Educação Básica 2007. Instituto Nacional de Estudos e Pesquisas Educacionais Anísio Teixeira. Brasília: Inep, 2009. 
PARANÁ. Lei Complementar n. 108. Diário Oficial do Estado, Curitiba, 10 maio 2005.

. Decreto n.o 4.230. Diário Oficial do Estado, Governo do Estado PR, 16 mar. 2020a.

. Decreto n. 4.320. Diário Oficial do Estado, Governo do Estado PR, , 23 mar. 2020b.

. Decreto n.o 4312. Diário Oficial do Estado, Governo do Estado PR, 20 mar. 2020c.

. Instituto Paranaense de Desenvolvimento Econômico e Social.

Disponível em: http://www.ipardes.pr.gov.br/. Acesso em: 16 out. 2020. Ipares, 2020d.

. Ofício Circular n.o 041/2020, DEDUC/SEED. Secretaria da Educação e do Esporte, Curitiba, 12 maio 2020 e.

. Ofício Circular n.o 047/2020, DEDUC/SEED. Secretaria da Educação e do Esporte, Curitiba, 29 maio $2020 f$.

. Orientação n. 07/2020, DEDUC/SEED. Secretaria da Educação e do Esporte, Curitiba, 28 abr. 2020g.

. Orientação n.o 04/2020, SEED/DPGE/DLE/CDE. Secretaria da Educação e do Esporte, Curitiba, 28 abr. 2020h.

. Processo n.o 32/2020, CEEPR. Conselho Estadual de Educação, Curitiba, 31 mar. 2020i.

. Resolução n. 1.014/2020, GS/SEED. Secretaria da Educação e do Esporte, Curitiba, 3 abr. 2020j.

. Resolução n.o 1.016/2020, GS/SEED. Secretaria da Educação do Esporte, Curitiba, 3 abr. 2020k. 
PARANÁ. Resolução n. 1.249/2020, GS/SEED. Secretaria da Educação e do Esporte, Curitiba, 20 abr. 2020 I.

. Resolução n.o 1.253/2020, GS/SEED. Secretaria da Educação e do Esporte, Curitiba, 28 abr. 2020m.

. Comunicado n.o 06/2020, CDE/DLE/DPGE/SEED. Secretaria da Educação e do Esporte, Curitiba, 07 maio 2020n.

. Resolução n.o 1.259/2020, GS/SEED. Secretaria da Educação e do Esporte, Curitiba, 28 abr. 2020o.

. Resolução n.o 1.522/2020, GS/SEED. Secretaria da Educação e do Esporte, Curitiba, 07 maio 2020p.

. Resolução n.o 1.611/2020, GS/SEED. Secretaria da Educação e do Esporte, Curitiba, 12 maio 2020q.

. Resolução n.o 1733/2020, GS/SEED. Secretaria da Educação e do Esporte, Curitiba, 15 maio 2020r.

. Resolução n.o 891/2020. Secretaria da Educação e do Esporte, Curitiba, 18 mar. 2020s.

SANTOS, B. S. A cruel pedagogia do vírus. Coimbra: Almedina, 2020.

YIN, R. Estudo de caso: planejamento e métodos. 5. ed. Porto Alegre: Bookman, 2015. 


\section{GESFORT \\ GRUPO DE PESQUISA \\ EDUCAÇÃO SUPERIOR, FORMAÇĀO E TRABALHO DOCENTE}

\section{O Grupo de Pesquisa "Educação Superior, Formação e Trabalho Docente" (GESFORT) e suas pesquisadoras}

O Grupo de Pesquisa "Educação Superior, Formação e Trabalho Docente" (GESFORT) é constituído por pesquisadoras oriundas da Universidade Estadual do Oeste do Paraná (UNIOESTE), campi de Francisco Beltrão e de Foz de Iguaçu, e conta com a parceria de pesquisadoras da Universidade Federal do Rio Grande do Sul (UFRGS), e de pesquisadoras vinculadas à Secretaria da Educação do Estado do Paraná (SEED).

Criado em julho de 2016, o grupo vem se consolidando como um espaço permanente de estudos, trocas de experiências e pesquisas considerando três dimensões articuladas. A primeira é a educação superior, entendida como o principal espaço da formação inicial de professores, e tem como responsabilidade social promover o processo formativo-educativo dos graduandos, nas dimensões profissionais, éticas, sociais, políticas e culturais. A segundo é a formação, considerada como o desenvolvimento do ser humano histórico-social, e se constitui de um conjunto de saberes e conhecimentos requeridos ao desempenho de funções sociais, no caso o trabalho docente. A terceira dimensão é a do trabalho, concebido a partir de seu aspecto ontológico, de criação histórico-social da vida humana, de visão geral, e está articulado à divisão social e técnica do trabalho. À luz desse entendimento, o grupo analisa a singularidade da formação e do trabalho docente, a especificidade, a profissionalização, as condições de trabalho, intensificadas e precarizadas, as quais interferem no processo formativo-educativo e no desempenho das funções requeridas socialmente. Essas três dimensões traduzem-se nas duas linhas de pesquisa cadastradas no Diretório de Grupos de Pesquisa do Brasil. São elas:

1) Educação Superior e Processos Formativos, que estuda as temáticas relacionadas às práticas institucionais e seus desdobramentos para os processos formativos. 
2) Formação e Trabalho Docente, que estuda as políticas para a formação dos professores, teorias e práticas pedagógicas e o trabalho docente nas diversas etapas e modalidades da educação básica e superior (DGPB, 2020). 
As fotos das autoras demonstram uma parte das condições do mundo real, enquanto pesquisavam também vivenciavam as (in)certezas do trabalho docente. A trajetória acadêmica das autoras pode ser consultada na Plataforma Lattes.

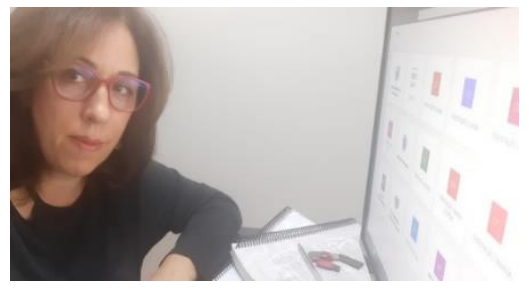

Ângela Maria Silveira Portelinha

Pós-doutoranda em educação pela Unicamp. Doutora em Educação pela UFRGS. Professora do Curso de Pedagogia e do Programa de Pós-Graduação em Educação da Universidade Estadual do Oeste do Paraná (Unioeste), campus de Francisco Beltrão. No momento da pesquisa coordenava o PPGEFB e desenvolvia as atividades de ensino, pesquisa e extensão. A foto representa o trabalho presencial substituído pelo virtual durante a pandemia: orientações, reuniões, aulas, cursos, palestras, produção de material para avaliação quadrienal da Capes, participação em bancas. A sobrecarga de trabalho resultou na necessidade de adequar o espaço da vida familiar às exigências da vida profissional.

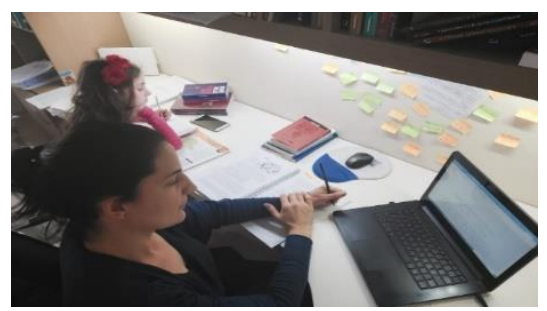

Berenice Lurdes Borssoi

Doutoranda em Educação pela Unicamp. Professora do Curso de Pedagogia da Universidade Estadual do Oeste do Paraná (Unioeste), campus de Foz do Iguaçu. A foto representa os estudantes da pós-graduação durante a pandemia, um cotidiano de estudos e realização de suas pesquisas. Com a produção da tese, deparou-se com a filha em processo de alfabetização necessitando de todo acompanhamento pedagógico, cuidados emocionais e organização do trabalho doméstico. Experienciou desafios de conciliar a vida de pesquisadora e as condições da mulher com a divisão social do trabalho. Diante a sobrecarga de atividades, a alternativa foi adentar trabalhando à noite, pela manhã com a casa adormecida, e fazendo uso do tempo de finais de semana com a divisão dos cuidados da filha com o esposo.

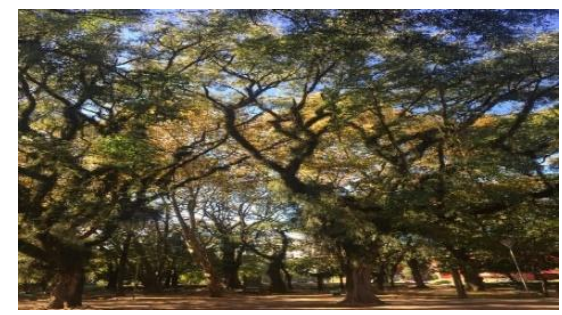

Egeslaine de Nez

Possui estágio pós-doutoral na PUCRS. Doutora em Educação pela UFRGS, é docente da Faculdade de Educação (Faced) - UFRGS. O silêncio do mundo e a ausência de "gente" são os destaques dessa foto, que indica o momento vivenciado no início da pandemia. Eu estava longe de casa, realizando o estágio pósdoutoral e a solidão se instalou nos meus dias de trabalho. "Só o colo acalma a saudade" (F. Carpinejar). $\mathrm{O}$ colo do sol, do parque olhando as nuvens, da praia escutando as ondas, do vento passando, de sair do cansaço, de dar a volta por cima, da normalidade, enfim, o colo do mundo. 


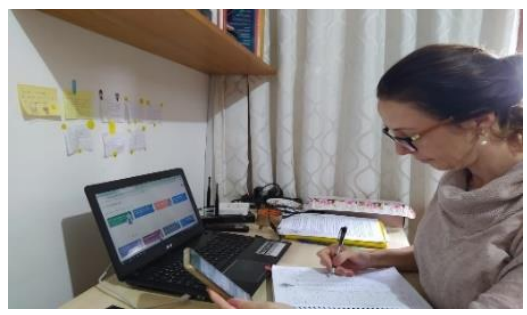

Franciele Maria David

Mestre em Educação pela Universidade Estadual do Oeste do Paraná (Unioeste). É professora pedagoga (coordenação pedagógica) da Educação Básica, professora do Curso Técnico Integrado Formação de Docentes, Subsequente do Administração e professora de Sociologia do Ensino Médio. A foto representa a intensificação do trabalho pedagógico neste período. Atendimento pelo celular, para pais, alunos, professores, direção e tutorias (NRE); classroom (sala de aula virtual), período em que o trabalho adentrou nossas casas e vidas privadas.

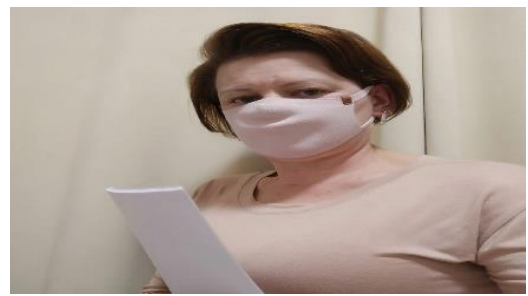

\section{Keila Cristina Batista}

Mestra em Educação pela Universidade Estadual do Oeste do Paraná (Unioeste), campus de Cascavel. Professora da rede municipal de Ampére. Pedagoga do estado do Paraná, é professora colaboradora da Faculdade de Ampére (Famper). A foto representa os/as pedagogos/as, professores/as durante a pandemia, a intensificação do trabalho docente, representado pela produção e entrega de materiais impressos aos estudantes que não têm acesso às ferramentas digitais.

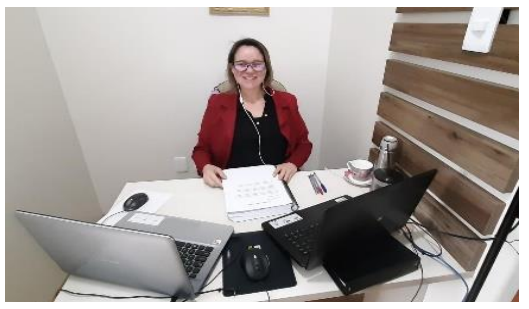

Vanice Schossler Sbardelotto

Doutora em Geografia pela Universidade Estadual do Oeste do Paraná (Unioeste), campus de Francisco Beltrão, onde leciona no curso de Pedagogia. A foto revela um momento importante da vida da pesquisadora: a defesa do doutorado, de maneira remota, em meio à pandemia, sem os tradicionais abraços fraternos. Evidencia também a solidão da escrita acadêmica, retrata o isolamento dos professores, cada um em seu lugar, com encontros mediados por tecnologias. Foi em meio à finalização e defesa da tese que a pesquisadora colaborou com o grupo na pesquisa aqui apresentada. A urgência em explicitar o momento vivido pelos professores fez com as duas pesquisas - a do doutorado e esta andassem de forma paralela. 
Afirmamos que caso seja infringido qualquer direito autoral, imediatamente, retiraremos a obra da internet. Reafirmamos que é vedada a comercialização deste produto.

$1^{a}$ Edição Julho de 2021

Navegando Publicações

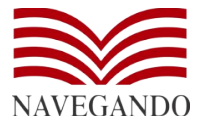

www.editoranavegando.com

editoranavegando@gmail.com

Uberlândia - MG 


\section{NAVEGANDO PUBLICAÇÕES}

Uma Editora vinculada ao Grupo de Estudos e Pesquisas "História, Sociedade e Educação no Brasil" - Histedbr - voltada à publicação de e-books para distribuição gratuita e livros impressos sobre temas científicos.

Nosso trabalho é de empreendedorismo social, procurando retornar para a sociedade acadêmica e estudantil possibilidades de conhecimento democrático, gratuito e justo.

Venha publicar conosco!

E-mail: editoranavegando@gmail.com

Site: www.editoranavegando.com 

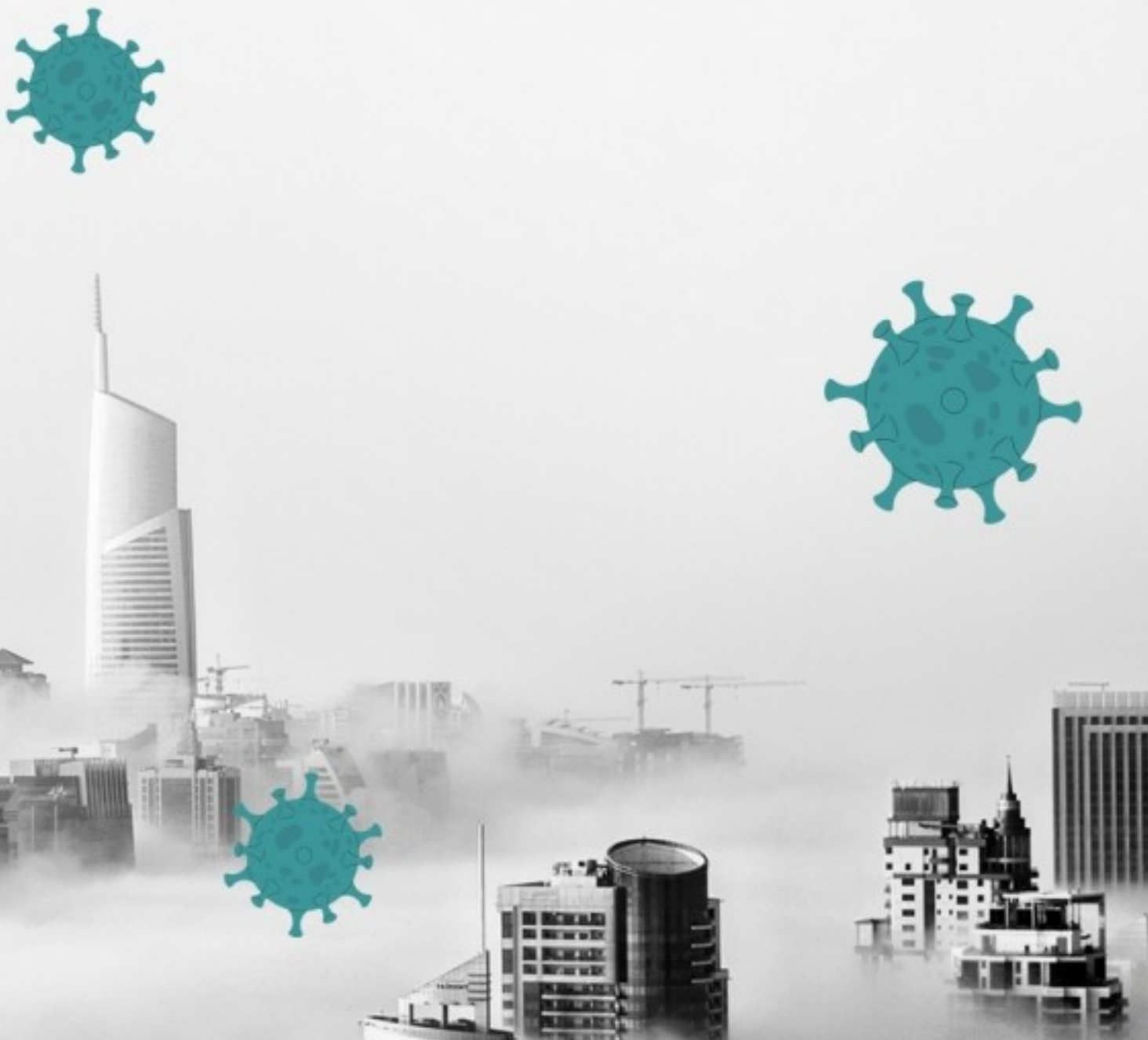

$\sqrt[P P G E F B]{\sqrt{\sqrt{\text { EDUCACÄO }}}}$
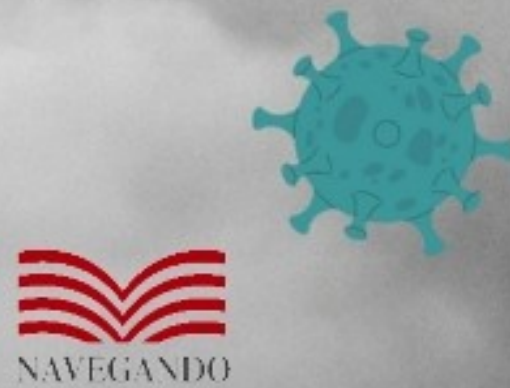